أثر قلق الإنفصال عن جماعة الرفاق فِ مستوى المسايرة الاجتماعية للدى عينة من الطلبة المراهقين يِّ قضاء حيفا

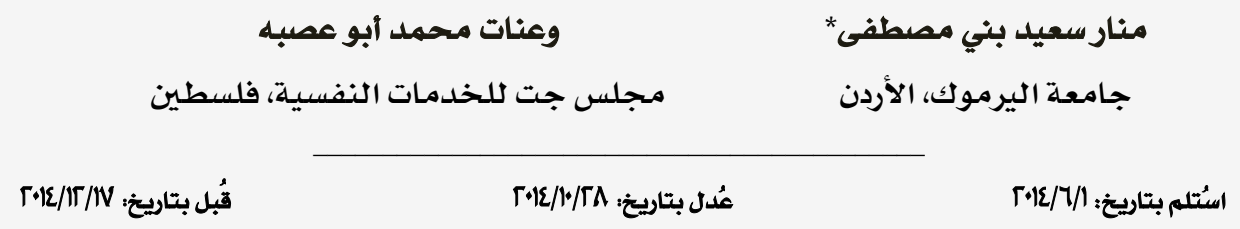

المستخلص: هدفت الدراسـة إلى التعرف على مستوى كل من قلق الاتفصال عن جماعة الرفاق والمسايرة الاجتماعية لدى عينة من الطلبة

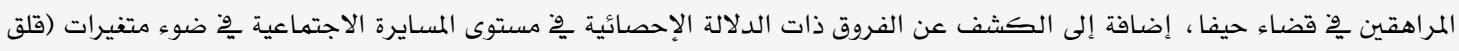

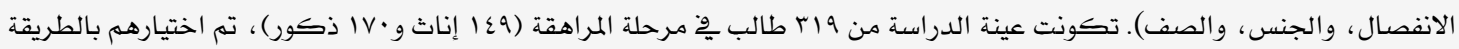

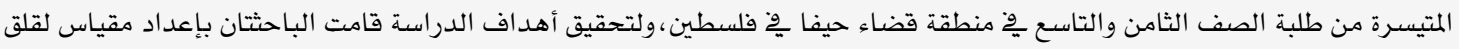
الانفصال عن الرفاق على غرار مقياس هانسبيرغ (Hansburg, 1980). كما استخدمتا مقياس المسايرة الاجتماعية الذي أعدته أبو نهر

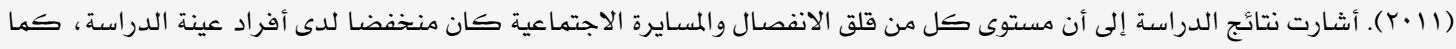
أشارت النتائج إلى عدم وجود فروق ذات دلالة إحصائية ِِّ مستوى المسايرة الاجتماعية تعزى إلى قلق الانفصال عن جماعة الرفاق، والجنس، والصف، وتفاعل الجنس وقلق الانفصال، وتفاعل الصف وقلق الانفصال، بينما وجدت فروق دالة إحصائيا ِِّ مستوى المسايرة الاجتماعية تعزى للتفاعل بين الجنس والصف، حيث كان مستوى المسايرة الاجتماعية أعلى لدى الإناث ِِّ الصف الثامن، بينما كان

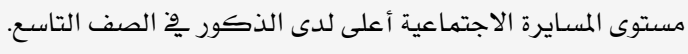
كلمات مفتاحية: قلق الانفصال، جماعة الرفاق، المسايرة الاجتماعية ، مرحلة المراهقة.

\title{
The Effect of Separation Anxiety from Peer Group on the Level of Conformity among a Sample of Adolescents in the District of Haifa
}

\author{
Manar S. Bani-Mustafa* \\ Yarmouk University, Jordan
}

\& Anat M. Abu-Asba

JET Councel for Psychological Services, Palestine

\begin{abstract}
This study aimed to explore separation anxiety and social conformity levels among a sample of adolescents. The study sample consisted of 319 students (170 males and 149 females). It was a convenient sample chosen from some villages in Haifa district in Palestine. The authors developed a scale to measure separation anxiety from peers after the model of Hansburg's 1980 scale. A measure of social conformity was also used (Abu-Nemr, 2011). The results showed a low level of separation anxiety and social conformity among adolescents. There were no significant differences found in social conformity due to the separation anxiety, sex, and interaction between anxiety and grade level. Significant differences were found in the level of social conformity that were attributed to interaction between sex and grade level in favor of males in the eighth grade and in favor of female in the ninth grade.
\end{abstract}

Keywords: Separation anxiety, peer group, social conformity, adolescence.

*manar.mostafa@yu.edu.jo 
وقيم عامـة متشابهة مها يعزز مـن الألفة بينهم

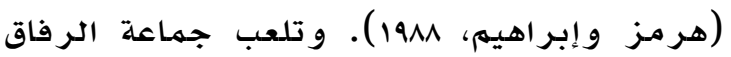

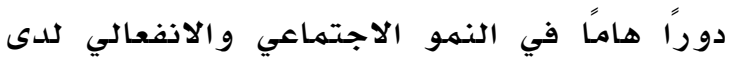
الهـر اهق في تزو ئد الوسائل لتحقيق الكفاية

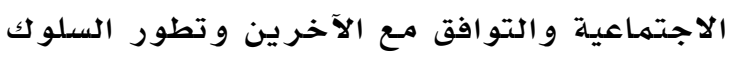

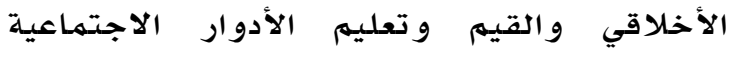

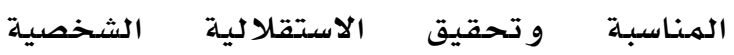
(Berns, 1997). إضافة إلى ذلك تجعل الكمل جماعة الرفاق الهر اهق أكثر واقعية في إدراكـه لنفسه

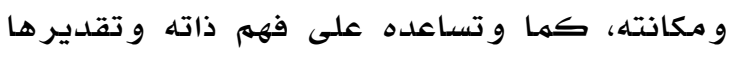

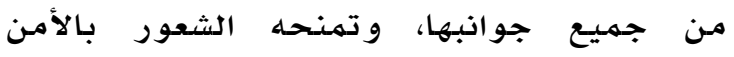

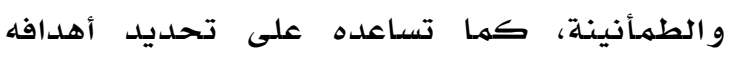

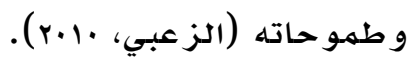

هذا ويعد الميل إلى تكوين جماعات الرفاق من

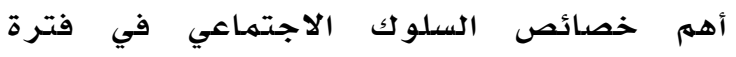

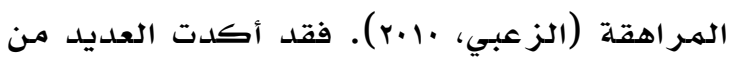

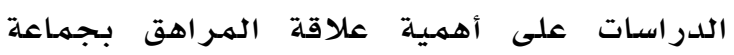

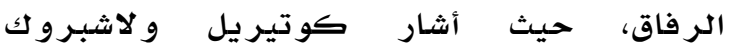
(Cotterell, 1996; Lashbrook, 2000)

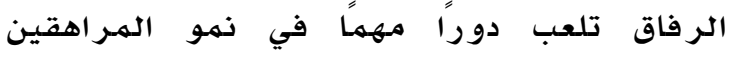
النفسي والاجتماعي وخاصدة فيما يتعلق بتشكيل

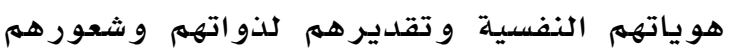
بالانتهماء. كما أكد كو لمان (Coleman, 1984)

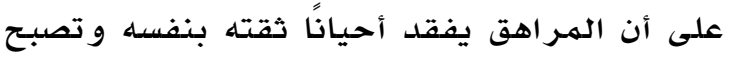
للديه التساؤلات حول هويته النفسية و مفهو مهل

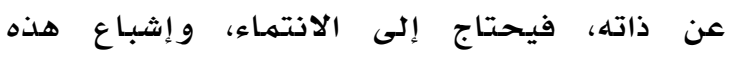
الحاجة يكون في ظل جماعة الرفاق إذ يشعر إداء

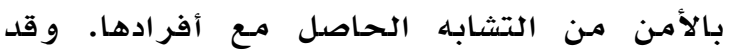

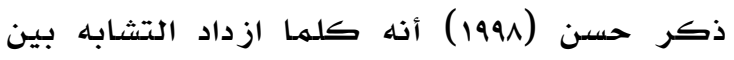
الفرد والجماعة - كلما ازداد الميل لأن تكون هذه الجماعة مقبولة كجماعة مرجعية، فحين

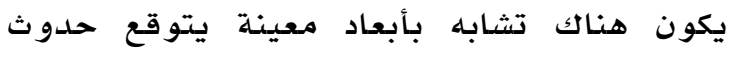
مستوى أعلى من المسايرة.

و تُعرّف المسايرة على أنها رغبة الفرد في تغيير

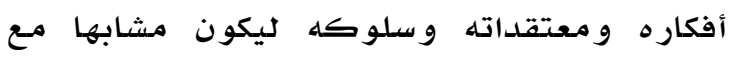

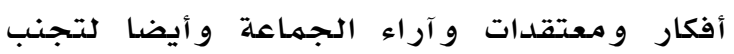
معارضة الجماعة ( Taylor, Peplau \& Sears, 2000). و يعرّف بوري (Boree, 1999) المسايرة،
تطرأ على الهـر اهق تغيرات كثيرة سواء كانت

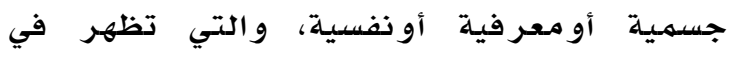

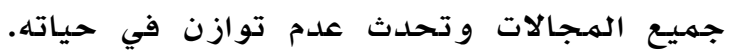

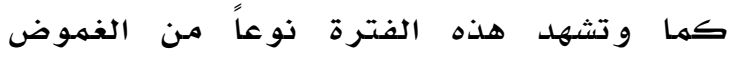

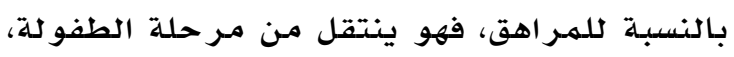
إلى مرحلة قبل الرشد، حيث يتلقى الهعاملة غير

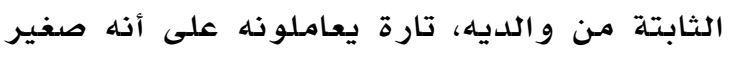
بحاجـة إلى الرعاية، وتارة أخرى يعتبرونه

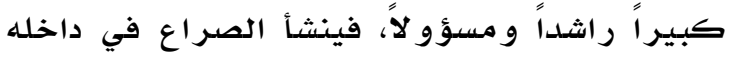

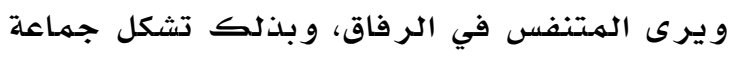

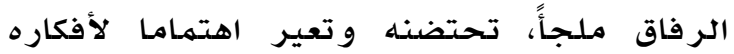

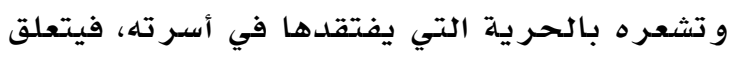

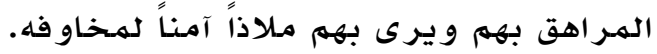

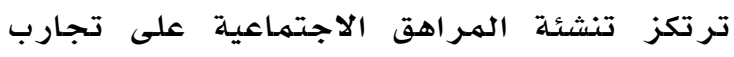

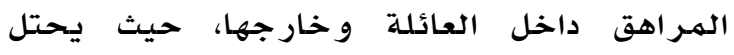

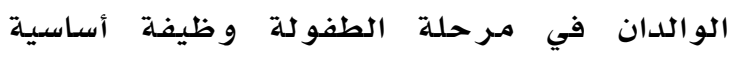

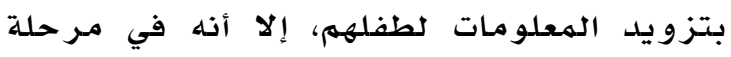

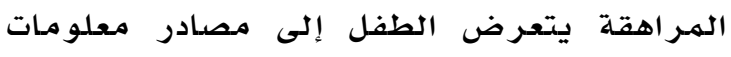

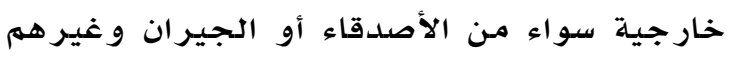

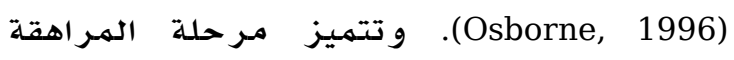

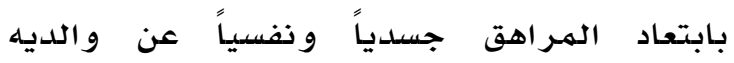
وتقربه الجسدي و النفسي من الأصدقاء في نفس وله

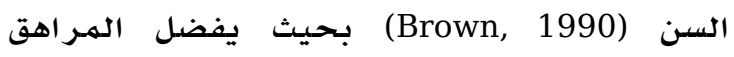
تكوين علاقات مبنية على المساواة مـع أصدقائه

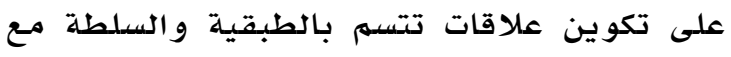

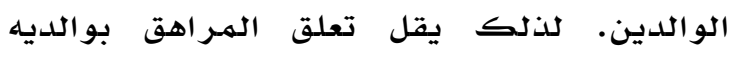
ويز يد تمسكه بر فاقه ( Brown, Eicher, \& Petrie, بولهيه

(1986)

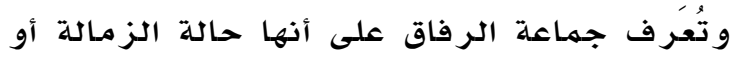

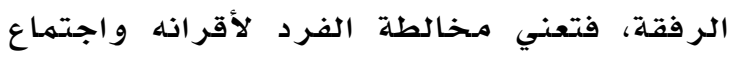

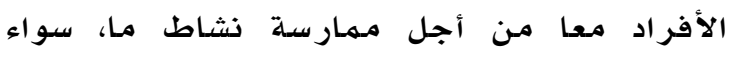

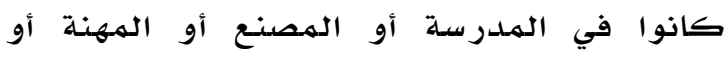

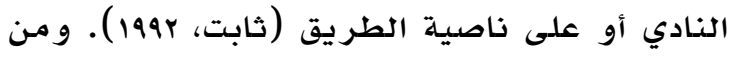

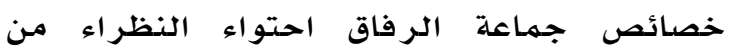

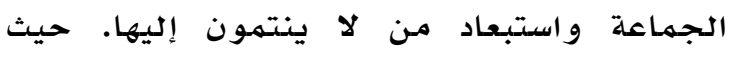
يتميز الاتصال بين الأعضاء بالوضوح و المبـاشرة بما في ذلك وضوح المعايير السلوكية الهتبعلة. كما يتشارك أعضاء جماعة الرفاق باتجاهات 
وتساعد على إحلال النظام داخل الجماعة لدرجة يصبح فيها سلولك الفرد متوقعا، من جهة أخرى

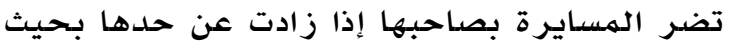

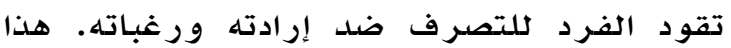
وقد تعمل المسايرة كسلوك يساعد على إثباع

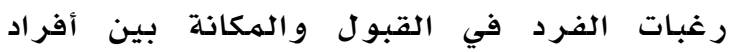

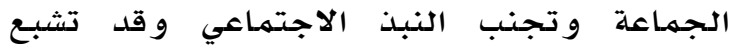

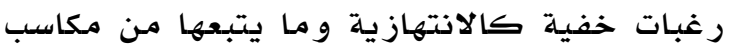

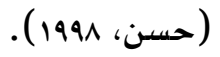

و في دراسة أجراها مزهر وقيصر ( \&azhar \&

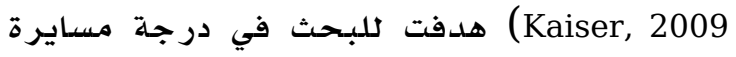
المرراهقين لأحكام جماعة الرفاق، حيث تلكونت

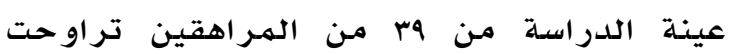

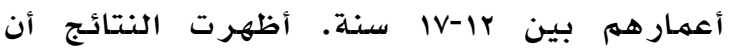

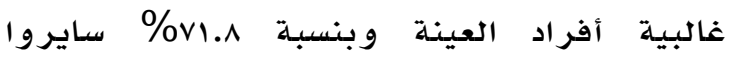
رفاقهم مـرة و احدة على الأقل.

و لقد ميز كل من دويتش وجير ارد ( \&eutsch \&

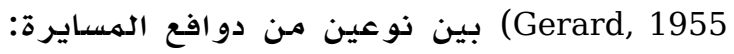
الدوافع الإعلامية وهي الرغبة في تشكيل تفسير

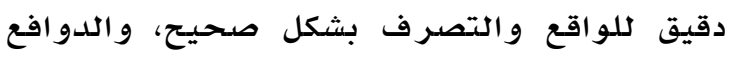

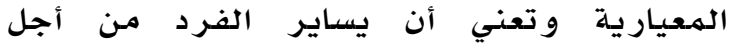

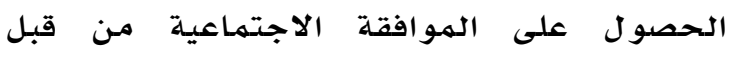

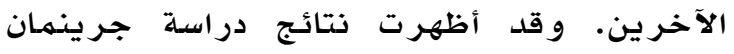
(Grinman, 2002)

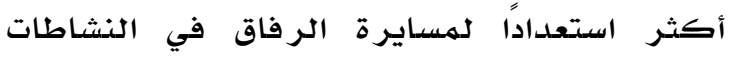

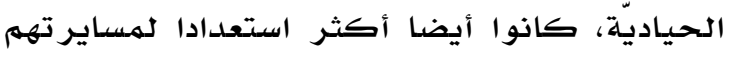

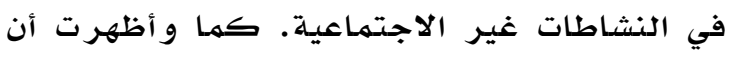

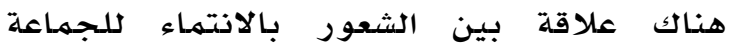

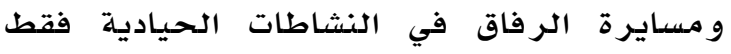
لدى الإناث.

و قد أشار كل من تايلور، بيبلو، وسيرز ( Taylor,

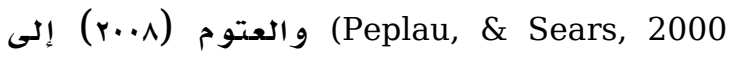
عدة أسباب لقيام الفرد بالمسايرة وهي اتباع السلوك السوي وذلك لشعور الفرد أن ما تفعله

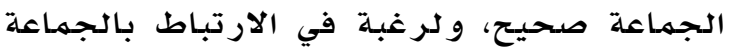

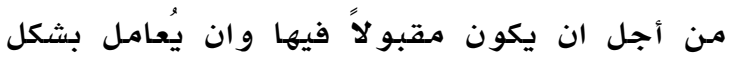

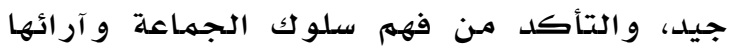

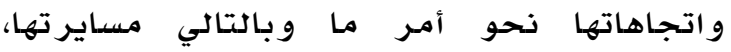
ورغبة في الحصدول على دعم لأفكاره و آرائه،
على أنها محاولة الفرد التقرب للموقف الجماعة الظاهر من حيث قرار اتها و أنشطتها و اتجاهاتها المختلفة حتى لا يظهر سلوكه منه مخالفا لسلوك الجماعة. و تحدث المسايرة عندما يدر كك الفرد أن أن

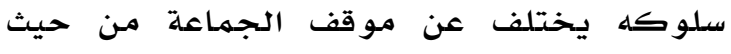

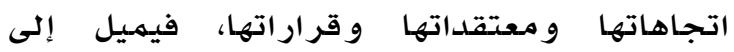
التحررك نحو موقفها نتيجة للضغوط الاجتهماعية الناتجة عن عدم الالتزام بمعايير الجمهاعة. و تحدث المسايرة عندما يتبنى الأفر اد اتجاهات أو

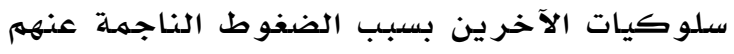
سواء كانت هذه الضغوط غير حقيقية ويتوهمها

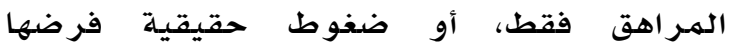

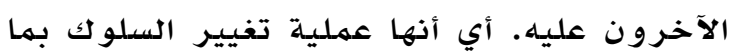
Cialdini \& ) يتناسب مـع استجابات الآخرين

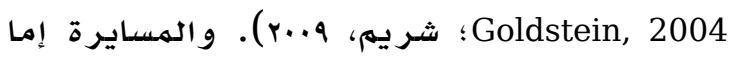
تكون أن علنية أو داخلية. العلنية تتجلى بأن

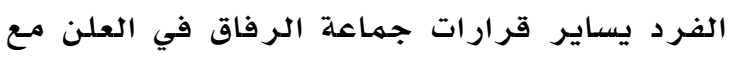

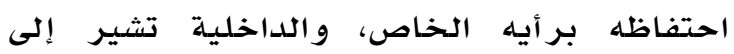

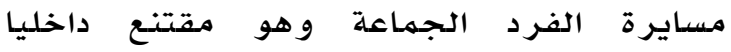
بقرار اتهم و لكنهله يرفض إعلان ذلك لعدة أسباب منها الخوف على مـركزه الاجتماعي و والخوف

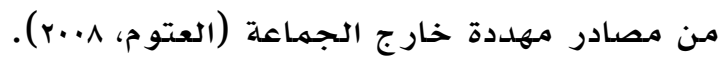
تعتمد قوة المسايرة على جاذبية الجماعة للفرد و على مدى تقبله لقيم واتجاهات و ومعايير

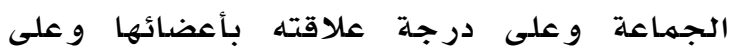
الوقت الذي يستغرقه للارتباط بها، يهدف الفرد من مساير ته لجماعة الرفاق كسب رضا رضا أعضائها،

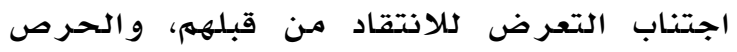

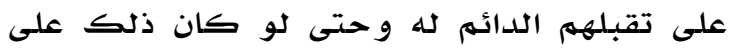

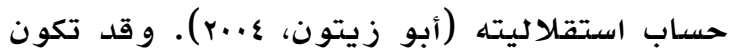
المسايرة سلوكا ايجابيا أو سلبيا. تأخذ المنحى لونى

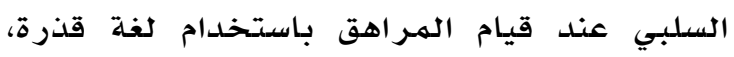
أو السر قة، أو الاستهز اء بالمعلمين و الو الدين و لكن

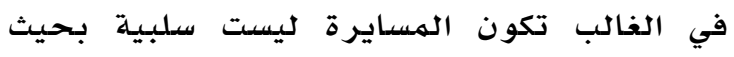
ير غب الهر اهقون في الاندماج بعاله الرفاق فيقضون معظم الوقت معهم ويلبسون ويتكلمون

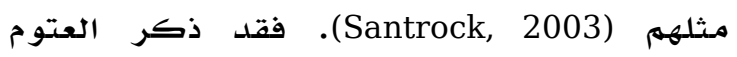

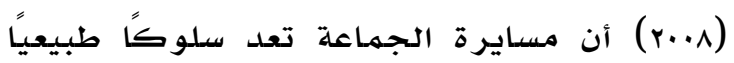
كواحدة من شروط التكامل والتآزر الاجتمهاعي بحيث تشجع على وحدة الجماعة وتماسكها 
الفرد على مواقف الانفصال. حيث تعتمد درجة ردود فعل الفرد على الانفصال على طبيعة وقوة مودة

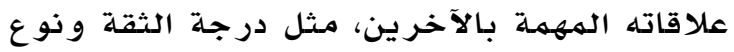
التعلق. ويعرف القلق بأنه حالة انفعالية غير سارة تمثل مزيجا من مشاعر الخوف المستمر و الفزع و الهمم تصيب الفرد عند توقع شر وشيك

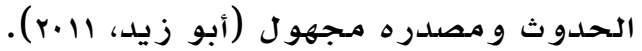
يرتبط مصطلح "الانفصال" بعلاقة الطفل مـع

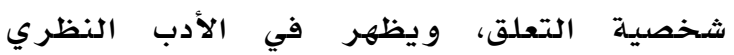
بشكلين أساسيين (Allen, 1955). المعنى الأول يربط الانفصال مـع أحداث يواجهها الفرد في الفيات حياته اليومية، ينفصل فيها عن الشخصيات

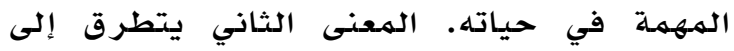
الانفصال كعملية نمائية طبيعية فيها انفصال نفسي تدريجي عن مصدر التعلق من خلاله ينهي

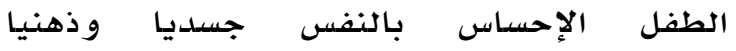
(Provence, 1987). و ويعرّف قلق الانفصال بأنه

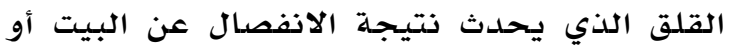

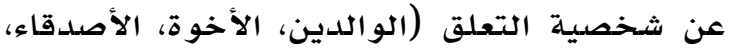

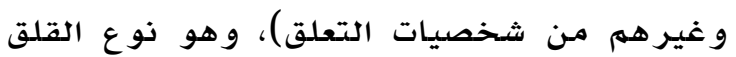

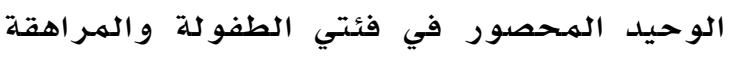
Cassidy ) و يعرّفه كاسيدي وشئهي (APA, 2000)

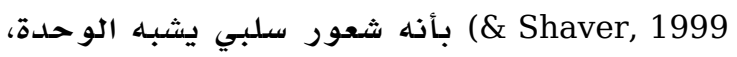
الفقدان أو الحزن ويحدث عندما ينفصل الفرد عن شخصية التعلق. كمها تم تعريفه على انه قلق الق

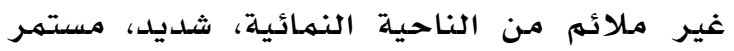

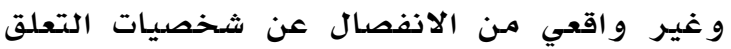
Dabkowska, Araskiewicz, Dabkowska \& ) .(Wilkosc, 2011

ويختلف قلق الانفصال من شخص لآخر ويتعلق

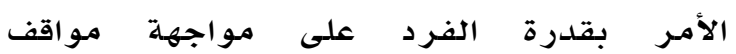
الانفصال. ردود فعل الفرد قد تكون معتدلة، مثل

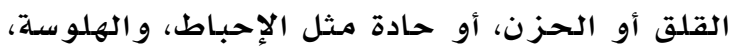

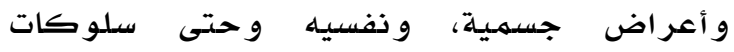
انتحارية (Eisen \& Schaefer, 2005). وقدم أشار

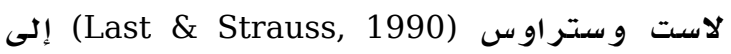
المظاهر المصاحبة لاضطراب قلق الانفصال، منها

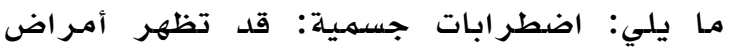
بدنية معدية أو معوية مثل آلام الهعدة والصداع الصداع

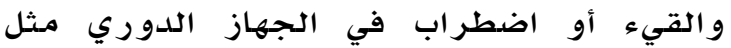

و تحقيق الانتماء للجماعة. و في المقابل أشارت دراسـة تينيسين و آخرون (تحقيق الانهاء

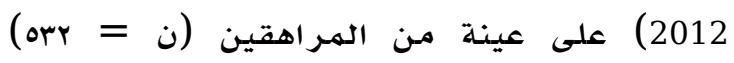

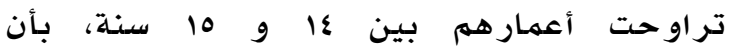

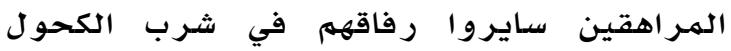
بشكل أكبر عندما كان الرفاق ذوو مكانة عالية في الجماعة، بهدف الحصول لعلى تقبلهيهم. وقد قدمت كوب (Cobb, 2001) تفسيرا لكون

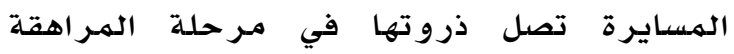
الهبكرة، بحيث ادعت أنها الهر حلة التي يبدأ بها

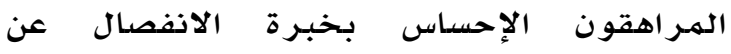
الوالدين، وعندئن يصبـحون أكثر تأثرا بأحكام

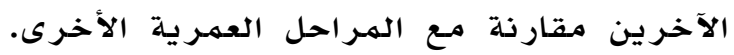
ونتيجة لذلك يكون للانفصال أثر في زئ زيادة الهرل

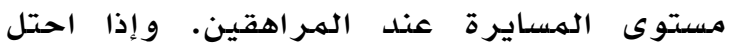

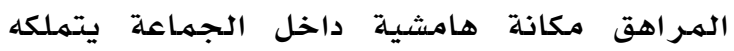
القلق نتيجة التعرض للرفض مـن الأقران ومـن أجل التقليل من مستوى هذا القلق يميل الى أن أن الن النيل يبالغ في المسايرة، من أجل الاحتفاظ بقبول

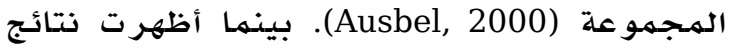

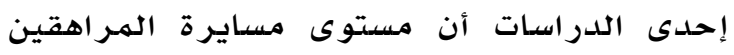

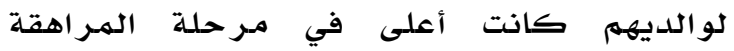
الهبكرة مقارنة بمسايرتهم لجماعة الرفاق، بينها

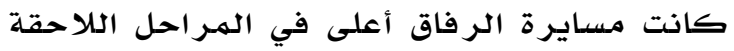

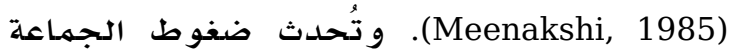

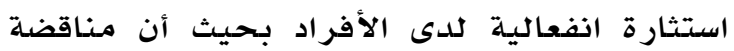

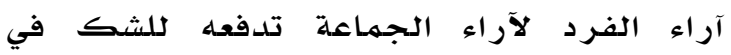

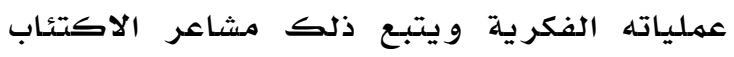
و العزلة، وهي حالة انفعالية تزيد من القابع ابلية

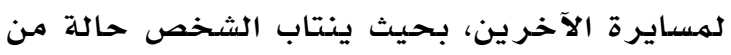

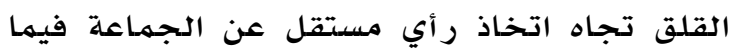

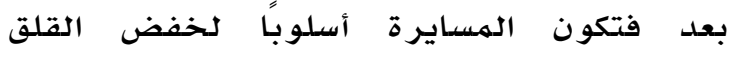
وتجنبـه و بذلك تشكل وظيفة دفاعية (حسن، .$(1991$

يعد بو لبي (Bowlby, 1973) من أو ائل من تطرق لقلق الانفصال وذلك عندما قدم نظريته عن

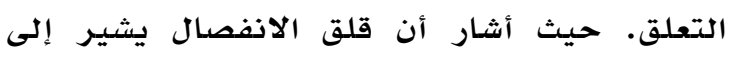

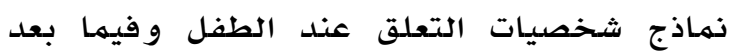
عند الراشد، والتي تؤثر بالطريقة التي يرد بها 
من جهة أخرى اقترح دابكوسكا وارازكيوكز

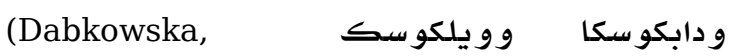
أن (Araskiewicz, Dabkowska \& Wilkosc, 2011

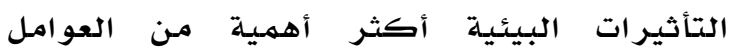

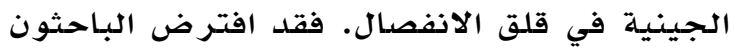
بأن حالات القلق ترتبط بالتعرض ضلق لحوادث الان الحياة

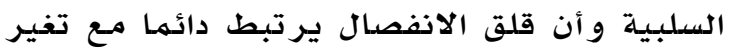

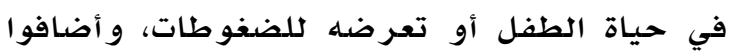

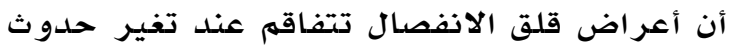

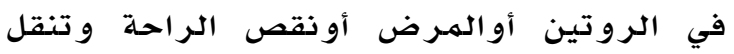

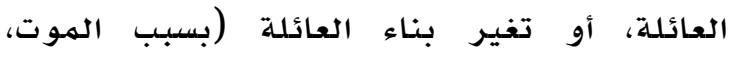

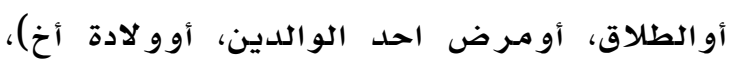

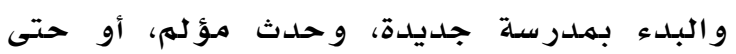
العودة إلى المدررسة بعد العطلة الصيفية.

و قد كشفت دراسلة مفرد وعبدالله و وأوبا عن علاقة (Mofrad, Abdullah \& Uba, 2010) قلق الانفصال بالتعلق إلى أنه مـن بين أنهاط

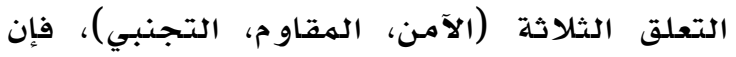

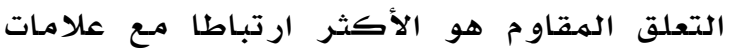
قلق الانفصال. العلامات مثل: الخوف مـن البقاء وحيدا و الخوف مـن أن يتم التخلي عنه.

هذا ويعتبر قلق الانفصال أحد أنواع القلق المنتشرة في المجتمهع بشكل عام وعند الأطفال

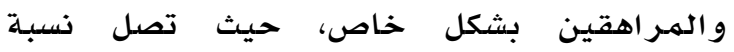
الأطفال الذين يعانون من قلق الانفصال بين ب-هرات

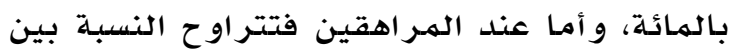

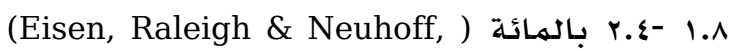
2008. و يختلف الانتشار حسب الجنس، بانس بحيث يعتبر قلق الانفصال أكثر شيوعا عند الإناث من Bowen, Lewinsohn, Hops \& Roberts, الذكور

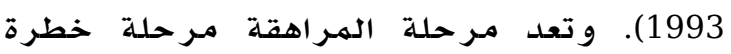

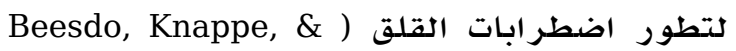
بحيث يعاني واحد من بين ثلاثة (Pine, 2009 مر اهقين من اضطر ابات القلق، وينتشر القلق عند بلد الإناث أكثر من الذكور ( Merikangas et al., الإناث

و يرتبط قلق الانفصال عند الهـراهقين بتغيرهم،

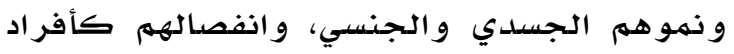

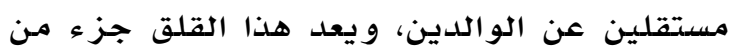

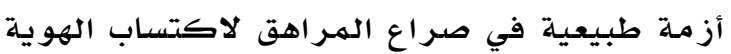

الشعور بضربات القلب، الدوخة والإغماء، بالذات

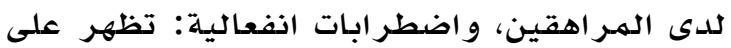

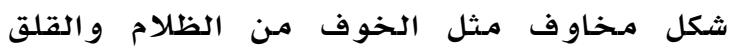

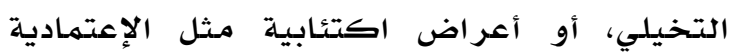

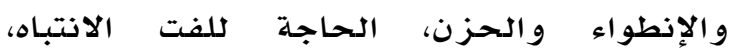

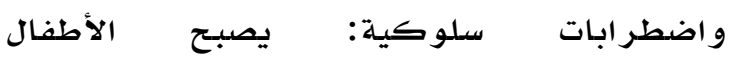
و المـر اهقين لحوحين و يتدخلون في شؤون الكبار

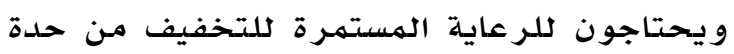
القلق لديهم، و اضطر ابات مدرسية: كالخوف من الذهاب للممدرسة والانسحاب الاجتماعي و التبلد وصعوبة التركيز أثناء اللعب أو الدرابة اسلة.

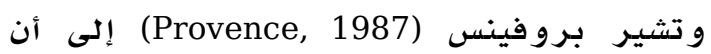
التأقلم مـع تجربية الانفصال هي مهمهـة مستمـرة مدى الحياة عند كل الأشخاص وهي ضرورية

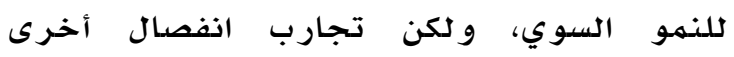
كتلك المتعلقة بفقدان أشخاص مهمين للفرد، ودي،

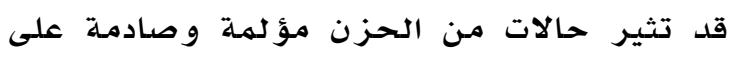
نحو خاص، ومن هنا فإن تجارب الانفصال يهـكن أن تسبب الإجهاد النفسي بمستويات مختلفية.

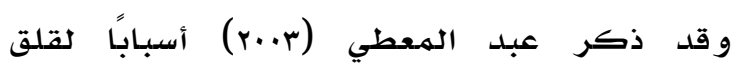
الانفصال كما يلي:العوامل النفسية الاجتماعية:

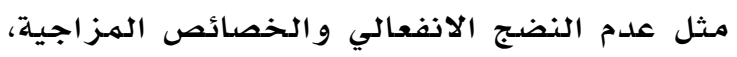

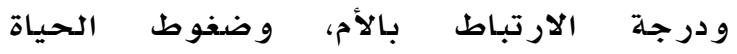
الخارجية. و عوامل التعله: أي عندما ينتقل قلق ورداهل

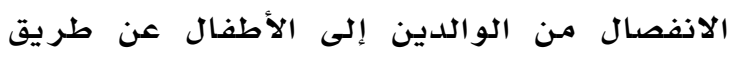

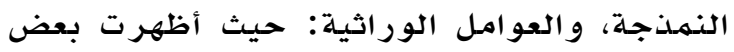

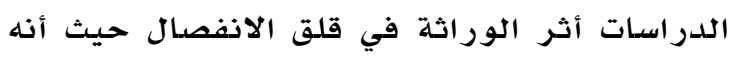

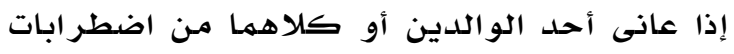

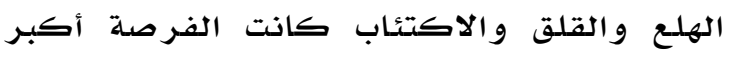
لأن يصاب الأبناء بقلق الانفصال ( Dabkowska, ) .(Araskiewicz, Dabkowska \& Wilkosc, 2011 كما أشارت دراسة كيرني وسيمز وبرسيل

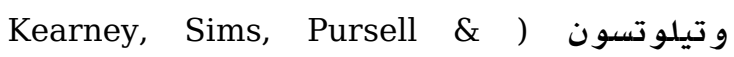

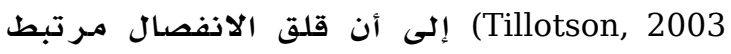

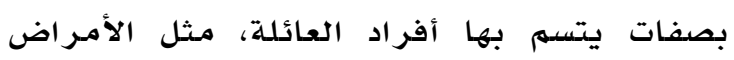

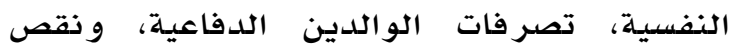

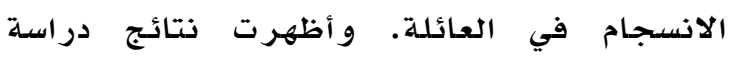
أخرى أن أعراض قلق الاض الانفصال عند البالغين تتعلق باضطراب قلق الانفصال عند الأطفال .(Seligman \& Wuyek, 2007) 
• • طالب، أظهرت النتائج أن هناك علاقة إيجابية

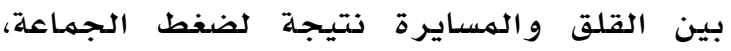
بحيث أن أفراد العينة أصبحوا قلقين عندما لقائا

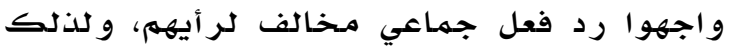

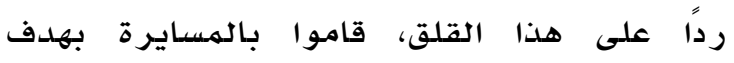

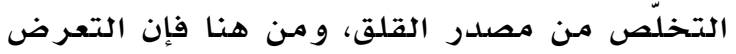

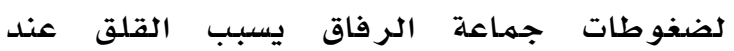

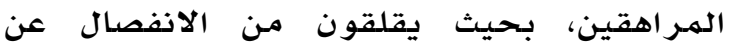
رفاقهم، ولذلك يلجئون إلى مساير تهم بهدف الآفهال بهن إزالة الشعور بالقلق.

\section{مشكلة الدراسة و أسئلتها}

يواجه المراهقين تغيرات كثيرة في حياتهم

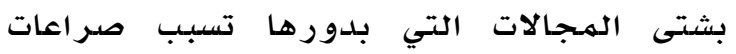
عديدة بداخلهم فيلجئون لأصدقائهم ويتعلقون بهم و لذلك يؤرقهم الانفصال عنهم. ومن هنا

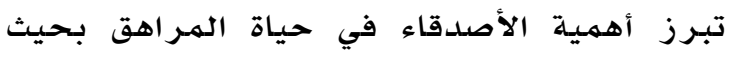

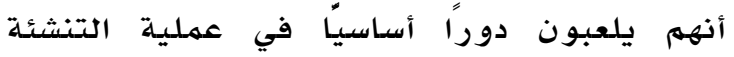

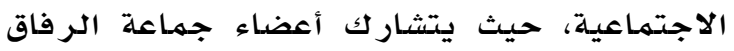
من المراهقين في كثير من الخصائص أهمها

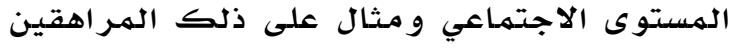

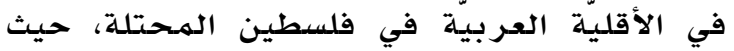
تشكل جماعة الرفاق مصدرا للدعم الاجتماعي

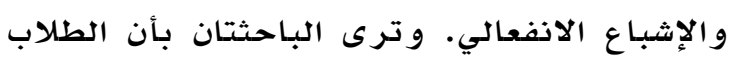

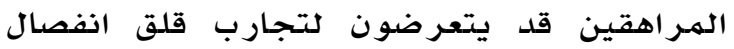

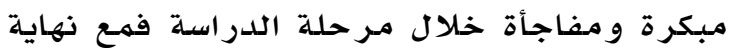

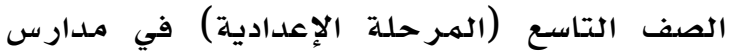

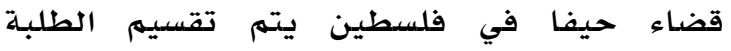

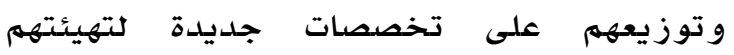

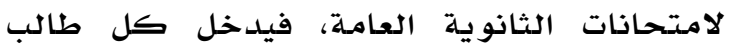
الصف العاشر بناء على التوزيع الذي تم من قبل

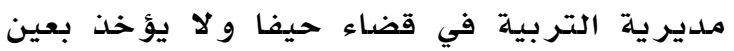

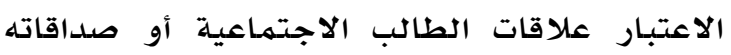

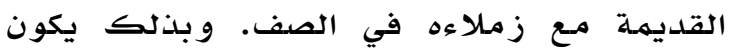
الانفصال عن الرفاق حتمي في هذه الهاه المرحلة.

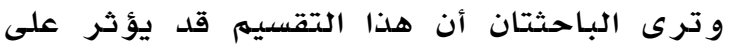

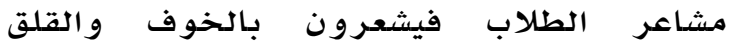
والتوتر من الانفصال عن أصدقاء صفهـه. لذا ستحاول هذه الدراسة الإجابة عن الأسئلة التالية:
والثقة بالنفس، وصراع بين رغبته في عيش الخدو الخصوصية و وتطوير الهوية الشخصية و وبين رغبته في العيش مـع أسرته وو الديه ( Wiesse \&

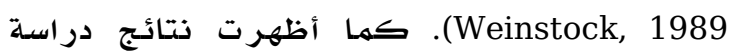
ستر اوس ولاهي وفريك وفريم ونايند (Strauss, Lahey, Frick, Frame \& Hynd, 1988) أن المراهقين الذين يعانون من قلق انفصال كانوا محبوبين بدرجة أقل من الأفراد العاديين

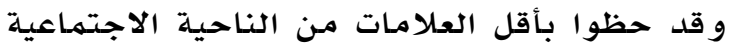

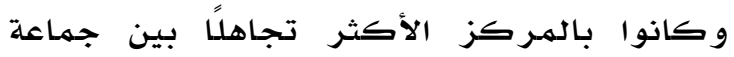
الر فاق مقار نة بباقي المجموعات. كما قد يظهر مستوى عال من قلق الانفصال

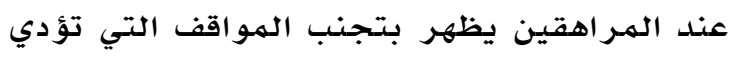

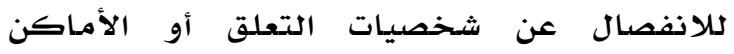

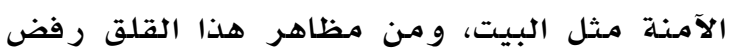

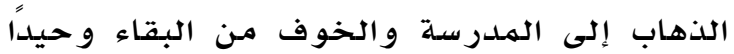

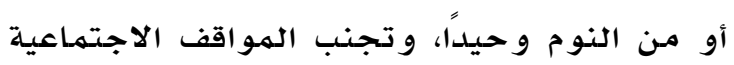

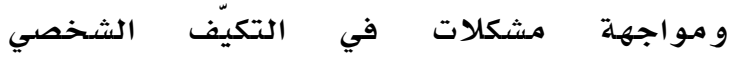

و الاجتماعي (Laible, Carlo \& Raffaelli, 2000). كما تشير الأبحاث إلى أن تجربة قلق الانفصال

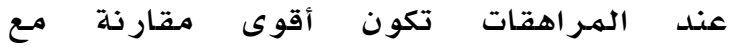

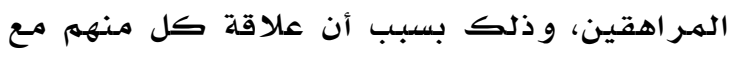
الوالدين تختلف. لكون أن البنات يملن إلى قضاء

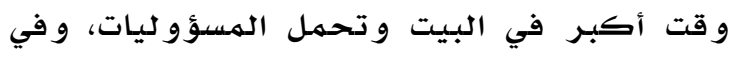

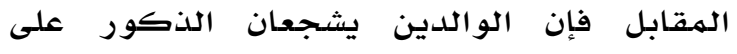

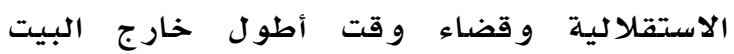
.(Dubas \& Gerris, 2002)

وقد اعتبر قلق الانفصال عند المراهقين عاملاً

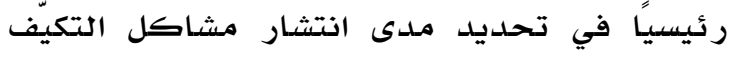

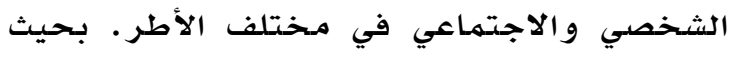
يتعرض المراهق لمشاكل تكيّيّة مختلفة، مثل الاهل

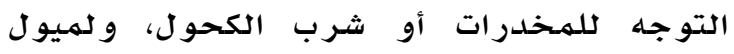

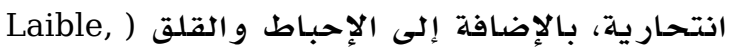

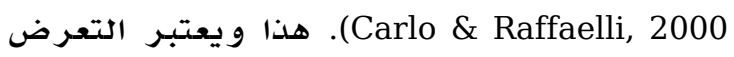
لضغوطات جماعة الرفاق واحد من أبرز أسباب القلق عند المر اهقين (Sontag \& Graber, 2011)

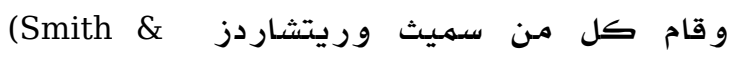
بدitchards, 1967) بين القلق والمسايرة. تكوّنت عينة الدراسة من لفحص العالاتة 
شخصية التعلق (الوالدين، الأخوة، الأصدقاء، وغير هم من شخصيات التعلق) (APA, 2000).

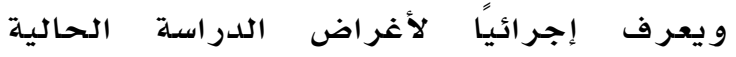
بالدرجة الكلية التي حصل عليـا عليها أفراد العينة

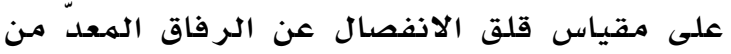
قبل الباحثتان في الدراسـة.

جماعة الرفاق: مجمهوعة من الناس الذين

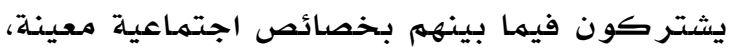

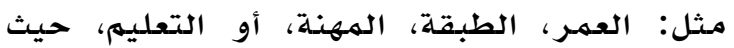
يكون التفاعل بمستوى من المساواة فيما بينهم. وقد يكون الفرد عضوا في عدة جماعات رفاق في في لفون

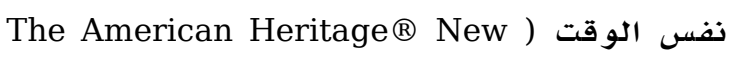
.(Dictionary of Cultural Literacy, 2012 المسايرة الاجتهماعية: تعرف المسدايرة على أنها

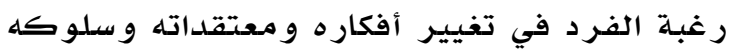

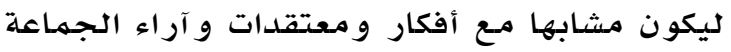
و أيضا لتجنب معار ضدة الجماعة ( Taylor, Peplau

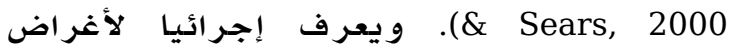

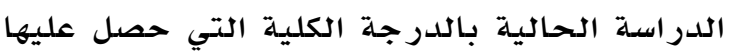

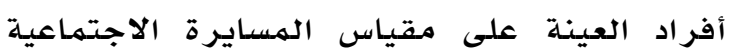
المعد من قبل الباحثتان في الدر اسـة.

\section{مجتمـع الدراسة}

تكون مجتمـع الدراسـة من طلاب الصف الثامن

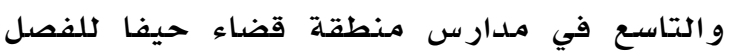

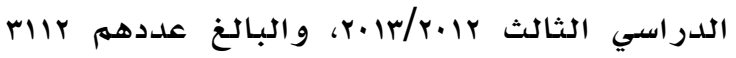
طالباً وطالبة حيث تم تحديدهم حسب السجلات الرسمية لمدير يـة تربية قضاء حيفا.

\section{عينة الدراسة}

تكوّنت عينة الدراسة من واب طالباً من طلاب الثامن و التاسـع في ع مدارس لقرى مـ منطقة

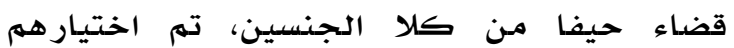

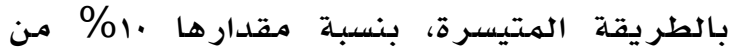

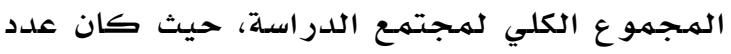

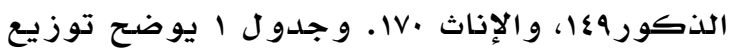

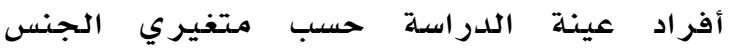

السؤال الأول: ما مستوى قلق الانفصال لدى الطلبة في مـرحلة المـر اهقة في قضاء حيفاي السؤال الثاني: ما مستوى المسايرة الاجتماعية لدى الطلبة في مـرحلة الهـراهقة في قضداء حيفاء السؤال الثالث: هل توجد فروق ذات دلالدة إحصائية في مستوى المسايرة الاجتماعية تعزى

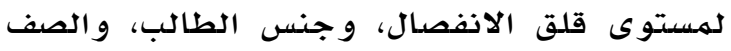

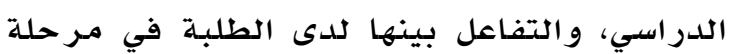
الهـر اهقة في قضداء حيفاء

أهمية الدراسة

تكمن أهمية الدراسة الحالية في الجانبين النظري و التطبيقي

الأهمية النظرية: للدراسة أهمية علميلة في

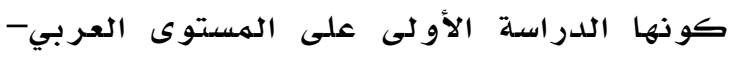
على حد عله الباحثتان- التي تفحص متغير قلق الانفصال عن جماعة الرفاق. كما تكمن أهميتها في تقديم الإطار النظري حول قلق التهاعه الانفصال عن

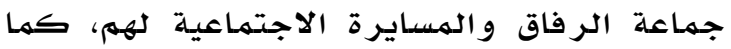

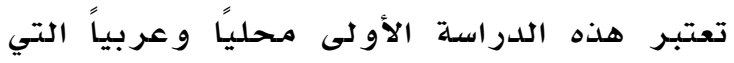
بحثت في أثر متغير قلق الانفصال عن جماعة الرفاق في درجة المسايرة الاجتماعية لهم في لهي قضاء حيفا.

الأهمية التطبيقية: تتجلى أهميلة هذه الدراسـة

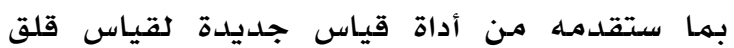

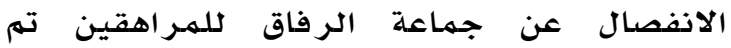

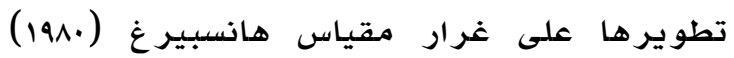
لقلق الانفصال عن الوالدين، بحيث يمكن أن

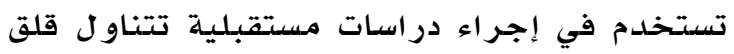

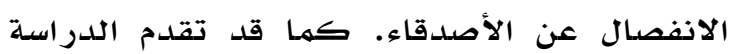

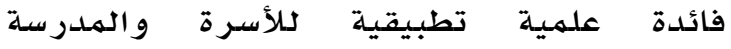
و المؤسسات الاجتماعية المهتلفة لفهيه لهيه لهياة الهـراهقين وسلوكاتهم و بالتالي تسهيل التعامل

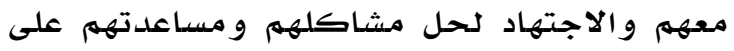
تقبل فكرة الانفصال عن جماعة الرفاق بلدون أي

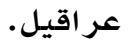

التعريفات الإجرائية

قلق الانفصال: يعرف قلق الانفصال بأنه القلق

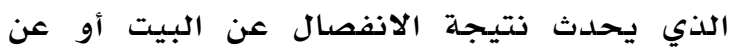


و القلق وردود الفعل الجسمية، خامسا: تجنب

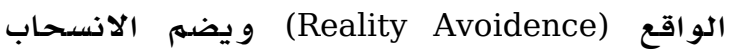

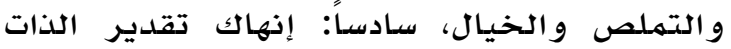
(Self-esteem Preoccupation) التركيز والتسامي، سـابعاً: فقدان حب الذات (Self-love Loss)

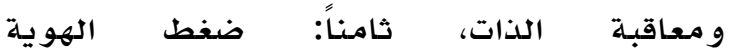
ويضهم أزمة الهوية، ويتمتع (Identity stress)

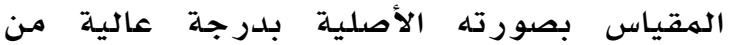

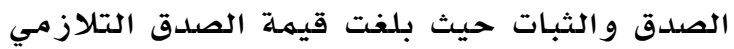

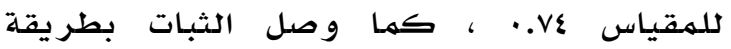

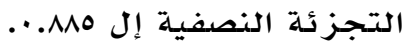

و في الدراسة الحالية قامت الباحثتان بتعريب مقياس قلق الانفصال وتعديله بهما يتناسب مـع البيئة العربية، وبما يتناسب مـع الهتغيرات في

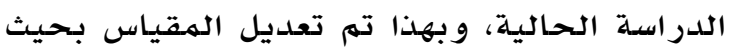
أصببح معدا لقياس قلق الانفصال عن جمـاعة

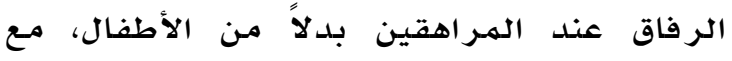
المحافظة على شكل الفقرات و عددها وتقسيهها

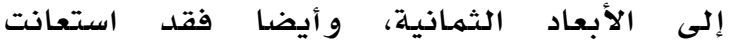

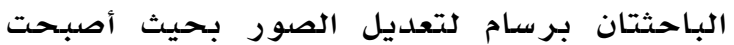
ملائمـة أكثر لمقياس قلق الانفصال عن الرفاق.

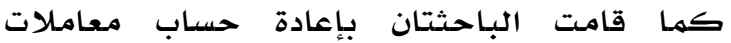
الصدق والثبات للمقياس بما يتناسب مـع متغير ات

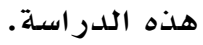

اولاً: صدق الهقياس في الدرراسلة الحالية: للتحقق من صدق المقياس في الدراسلة الحالية قامت الباحثتان باستخدام: مئ صدق المحتوى (المحكمين): حيث قامت

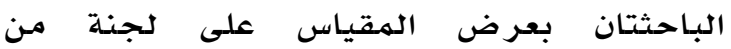

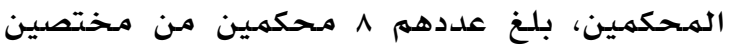
علم النفس التربوي والإرشاد النفسي في جامعحة

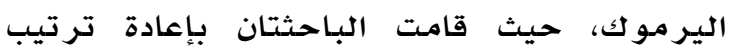
الفقرات فأصبحت موحدة على كل الصور (الفقرات التي تمثل الميكانيزمات الدفاعية بنفس موحس

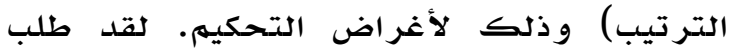
منهم إبداء الر أي في فقرات المقياس من حيث

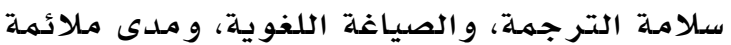
الصور للمقياس، ومدى انتماء الفقرة للبعد،
جدول 1

\begin{tabular}{|c|c|c|c|}
\hline المجموع & إناث & ذكور & الصف \\
\hline 114 & Tr & 01 & الصف الثامن \\
\hline$r \cdot T$ & $1 \cdot 1$ & 91 & الصف التاسع \\
\hline 119 & IV. & $1 \leqslant 9$ & المجموع \\
\hline
\end{tabular}

أدوات الدراسة

من أجل الإجابة عن أسئلة الدراسـة قامت الباحثتان باستخدام مقياس قلق الانفصال الذي أعدته الباحثتان على غرار مقياس هانسبيرغ

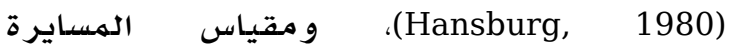

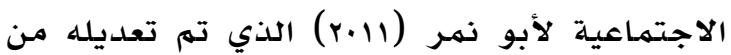
قبل الباحثتان في الدر اسـة الحالية.

مقياس قلق الانفصال

قامت الباحثتان في الدراسلة الحالية بإعداد

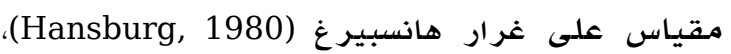

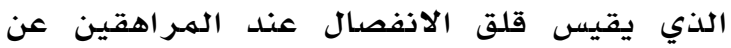

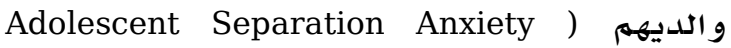
Ir Test صورة مرسومـة بالأبيض والأسدود لأطفال يمرون

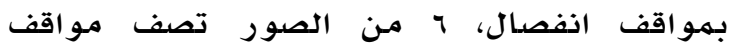
انفصال سهلة (مثال: الأم وضعت لتوها الطفل

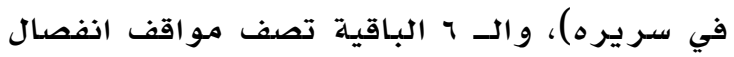

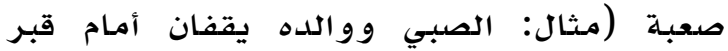

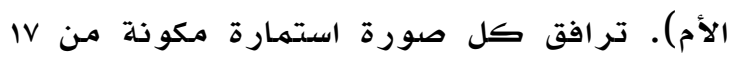
فقرة، وعلى المفحوصين الإثارة إلى الفقرات

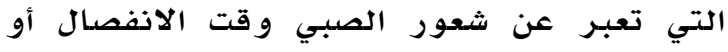

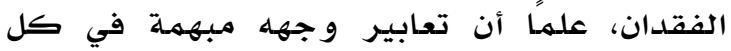
الصدور (تاركاً المجال لخيال المفحوص لتصدال لتصور شعور الصبي في ذلك الموقف). جميع الفقرات

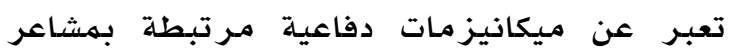

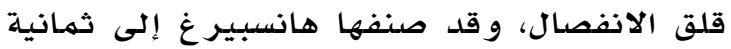

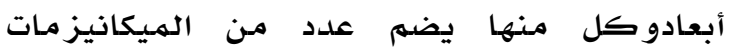

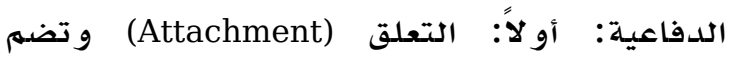

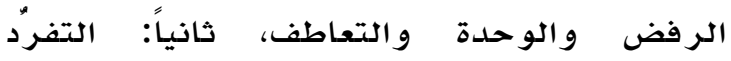
وتضم ادعاء الصحة النفسية (Individuation) و التكيف و التسامي، ثالثاً: العدووانية (Hostility) و تضمى الغضب والإسقاط ومعاقبة الذات، رابعاً: التوتر الهؤله (Painful Tension) و يضهم الخوف ؤف 
الاتساق الداخلي لهقياس قلق الانفصال ككل

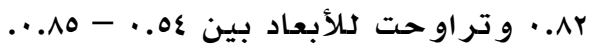
جدول r

قيم معاملات كرونباخ ألفا وارتباط بيرسون (ثبات الاعادة)

\begin{tabular}{|c|c|c|}
\hline \multicolumn{3}{|c|}{ للأبعاد والمقياس ككل } \\
\hline 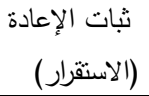 & كرونباخ & البعد البعد \\
\hline$\because V V$ &.$V r$ & تعلق \\
\hline 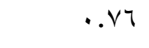 &.$\cdot v 1$ & تقرد \\
\hline$\because V T$ & $\cdot v^{\prime}$ & عدوانية \\
\hline . . &.$A r$ & توتر مؤلم \\
\hline. $.7 V$ & .77 & تجنب الواقع \\
\hline .110 &. .11 & إنهاك تقدير الذات \\
\hline .07 & $.0 \leqslant$ & فقدان حب الذات \\
\hline.$\wedge \mathrm{V}$ & .110 & ضغط الهوية \\
\hline.$\wedge \varepsilon$ &..$A r$ & المقياس ككل \\
\hline
\end{tabular}

تصديح مقياس قلق الانفصال: بلغ عدد الفقرات على كل صورة IV فقرة، فيما بلغ عدد الصور r إ صورة، وبذلك و وصل عدد الفقرات الكلي إلى بلى

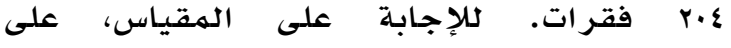

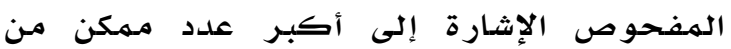
الفقرات التي تلائم كل صورة، وتحسب علامته على كل بعد، ويأخذ الطالب علامسة كليّة تمثل كل الأبعاد. و للحكم على مستوى قلق الانفصال،

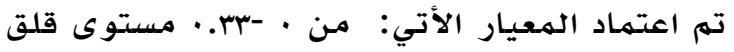

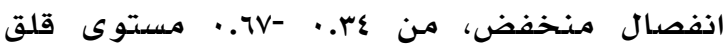

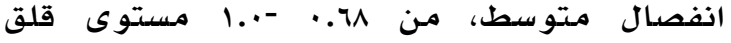
انفصال مـرتفع · مدول

\section{مقياس المسايرة الاجتماعية}

قامت الباحثتان باستخدام مقياس المسايرة

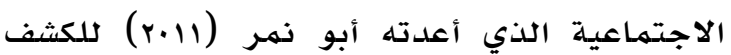

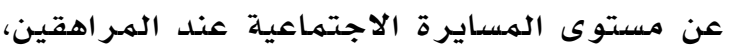
وقد اعتمددت أبو نمر أسلوب التقرير الذاتي في قياس مستوى المسايرة لدى أفراد العينـة. يحتوي المقياس بصورته الأصلية على بالى فقرة، و تتهم الإجابة عنه باختيار إجابة واحدة من ثلاثة

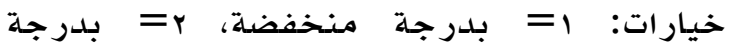

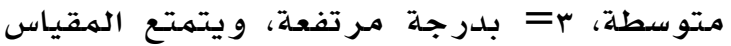
بصدورته الأصلية بصدق الهـكمين والصدق

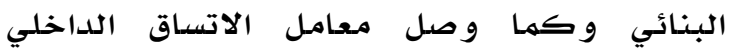
للمقياس إلى דV.. •. أما في الدراسـة الحالية فقد
و مدى انتمائها للمقياس، و كذلك مدى ملائمتها للبيئة العربية، وبناء على آرائهم تم إجر اء بعض

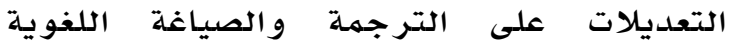

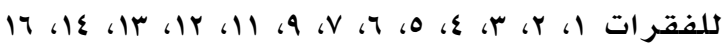
في كل صورة من الصور، وتعديلات على

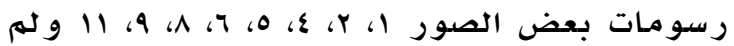
يتم حذف أي فقرة أو صورة.

الصدق التلازمي: استخدمت الباحثتان الصدق التلازمي للتأكد من صدق الهقياس، حيث تم

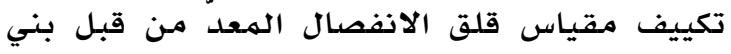
مصطفى و الشر يفين (Y. r) بما يتناسب مـع هدف

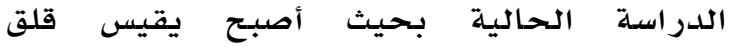

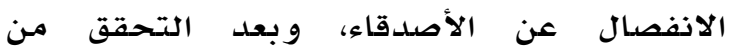
مؤشر ات صدقه وثباته، تم تطبيقه بشكل متز امـن مـع مقياس قلق الانفصال الهعد من قبل الباحثة فئل على غرار مقياس هانسبيرغ (Hansburg, 1980)، معياسل على عينة استطلاعية بلغت اء طالبا وطالبـة من

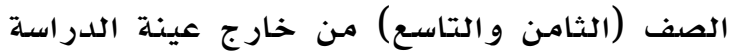
الأصلية، وحسب معامل الارتباط بين المقياسين

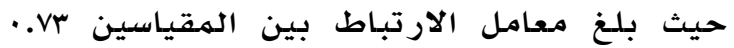
و الذي اعتبر مؤشرا مناسبا لصدق المقياس في الدر اسـة الحالية. ثانياً: ثبات المقياس في الدراسـة الحالية: لتقدير

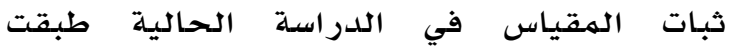
الباحثتان المقياس بصورته النهائية مرتين على الى لهئ

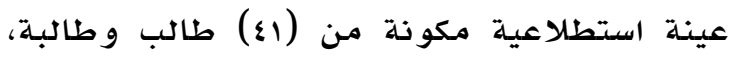

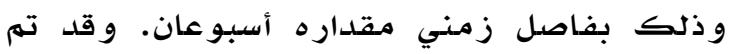
تقدير ثبات الإعادة بحساب معامل الارتباط بين درجات المفحوصين على المقياس في مـرّي

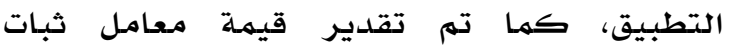
الاتسـاق الداخلي للمقياس باستخدام معادلة كرو نباخ ألفا، و جدو ل r يوضسح ذلك. كما هو مبين في جدول با بات تراوحت قيهم

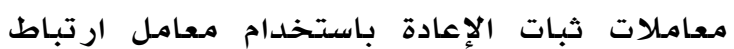

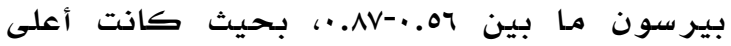
قيمة لبعد ضغط الهوية، و أدنى قيمـة لبعد فقدان

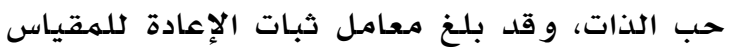
ككل ع^.•. في حين بلغت قيمـة معامل ثبات 
جدول rallo

\begin{tabular}{|c|c|c|c|}
\hline \multicolumn{4}{|c|}{ قيم معاملات ارتباط الفقرات بالمقياس ككل } \\
\hline معامل الارتباط & 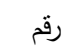 & معامل الارتباط & 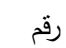 \\
\hline مع المقياس & 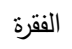 & 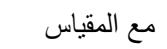 & 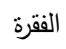 \\
\hline$\cdot . \leqslant 0$ & r & $\cdot .71$ & ○ \\
\hline. .01 & $1 \leq$ & $\cdot . \varepsilon r$ & 7 \\
\hline$. . T \leq$ & 10 & $\cdot . \varepsilon r$ & $\checkmark$ \\
\hline & & $\cdot . \leqslant 9$ & $\wedge$ \\
\hline
\end{tabular}

كما هو موضح في جدول م فإن قيهم معاملات

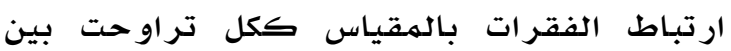

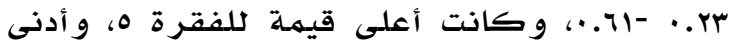
قيمة للفقرة 9. الحالية. وقد قامت الباحثتان بالتأكد مـن ثبات المقياس بطريقة إعادة الاختبار (Test-Re Test)، حيث طبقت المقياس بصورته النهائية على عينة استطلاعية مكونة من اء طالب و طالبة من طلاب الثامن والتاسـع، وذلك بفاصل زمني مقداره

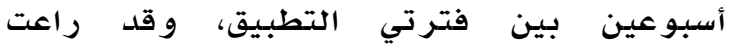

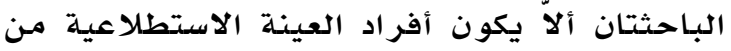

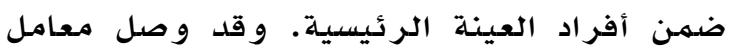
الارتباط بين نتائج الهفحوصين على الهقياس

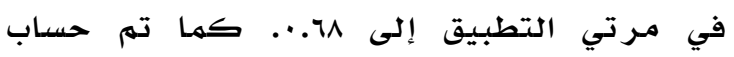
معامل ثبات الهقياس باستخدام معادلة كرونباخ

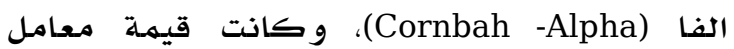
ثبات الاتساق الداخلي للمقياس به...، حيث

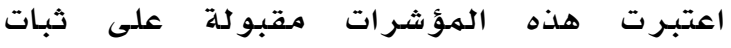
المقياس لأغر اض الدر اسلة الحالية.

قامت الباحثتان بتصحيح مقياس الهسايرة

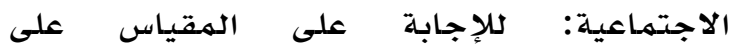
الهفحوص الإثارة إلى مـا يناسبـه من الخيارات

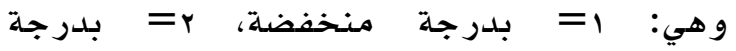

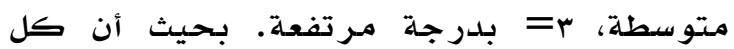
الفقرات إيجابية. و للحكمم على مستوى الهسايرة

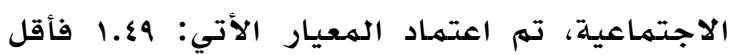

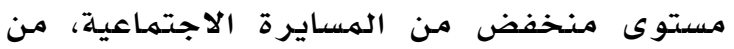

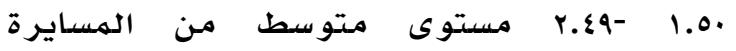

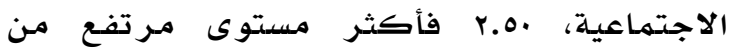
المسايرة الاجتهماعية.
قامت الباحثتان بزيادة عدد الفقرات مستعينة

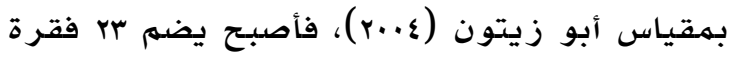

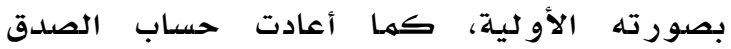
و الثبات للمقياس.

صدق و وثبات المقياس في الدراسلة الحالية: للتحقق من صدق المقياس في الدراسة الحالية قامت الباحثتان بقياس:

صدق المحتوى: قامت الباحثتان بعرض المقياس

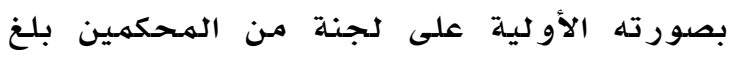
عددهم ^ مـحكمين من أساتذة علهم النفس

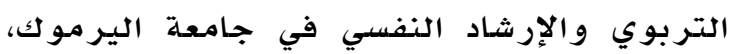

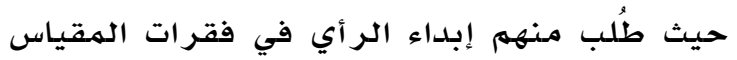

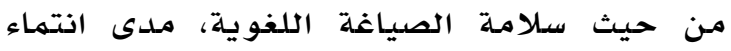
كل فقرة للمقياس، ومدى انتماء الفقرة للفئة

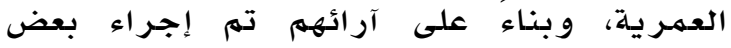

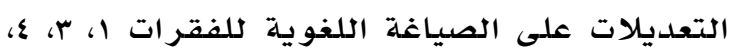

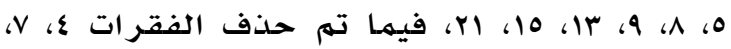

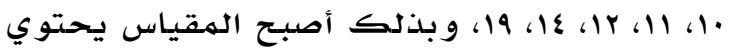
على 17 فقرة. صدق البناء: قامت الباحثتان بالتأكد من من مؤشرات صدق البناء عن طريق تطبيق المقياس بصورته الأصلية على عينة استطلاعية بلغت إئل طالبا من خارج عينة الدراسـة. و لأغراض صله صدئه البناء، تم حساب درجة ارتباط كل فل فقرة بالدرجة الكلية للمقياس، وقد اعتمدت البـاءل الباحثتان معيارين لقبول الفقرات وهما الدالة الإحصدائية

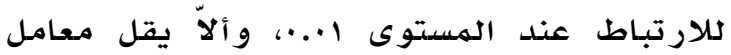
الارتباط عن •r..•، وبناء” على ذلك تهم استبعاد الفقرة 7 ليصبـ عدد فقرات الهقياس بصدورته

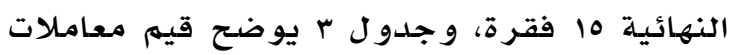
ارتباط الفقر ات بالمقياس ككل.

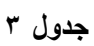

\begin{tabular}{|c|c|c|c|}
\hline \multicolumn{4}{|c|}{ قيم معاملات ارتباط الفقرات بالمقياس ككل } \\
\hline 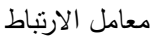 & 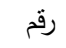 & معامل الارتباط & 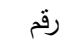 \\
\hline مع المقياس & 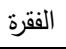 & مع المقياس & 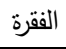 \\
\hline 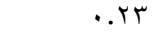 & 9 & •. & 1 \\
\hline. $.0 \mathrm{~V}$ & 1. &. $.0 \mathrm{~V}$ & r \\
\hline זr. & 11 & $.0 \mathrm{~V}$ & $r$ \\
\hline..$\leqslant r$ & Kr & .7 . & $\varepsilon$ \\
\hline
\end{tabular}




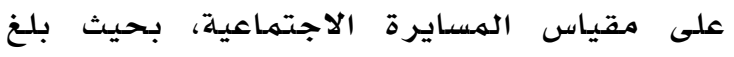

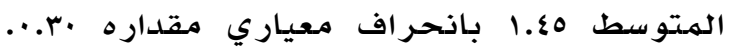
وقد تم تصنيفه منـخفضا بالنظر للمعايير التي مئي

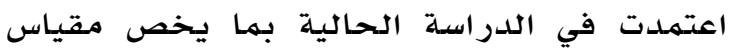
المسايرة الاجتماعية.

ثالثاً: النتائج الهتعلقة بالسؤال الثالث: هل توجد فروق ذات دلالة إحصائية في مستوى المسايرة

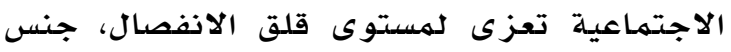

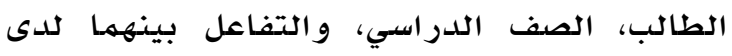
الطلبـة في مـرحلة الهـر اهقة في قضاء حيفاء للإجابة عن هذا السؤال، قامت الباحثتان بحساب

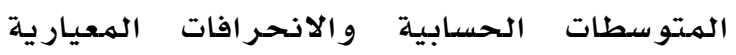

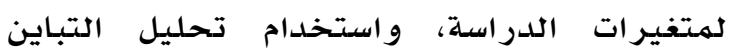
الثلاثي بتفاعلات ثنائية، كما هو موضح في جلدو ل 0. يتضح من جدول ه وجود عدة فروقات ظاهرة بين المتوسطات الحسابية التي تخص الهـو الهسايرة الاجتماعية تبعا لفئات كل من متغير ات الدراسلة:

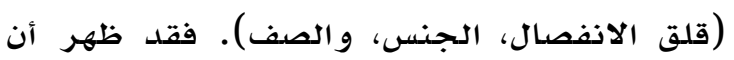

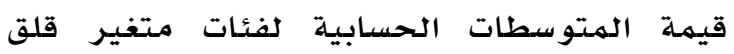

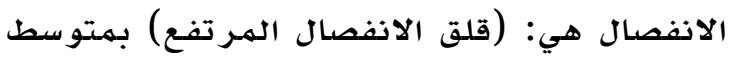
حسابي 1.09، ثم (قلق الانفيال الانصال المتوسط)

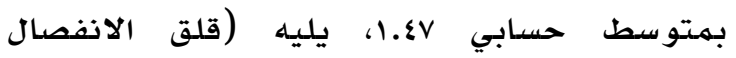

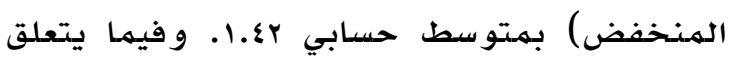
بمتغير الجنس فيظهر أن المتوسط الحسابي للذكور ألذوا أعلى من المتوسط الحسابي للإِناث

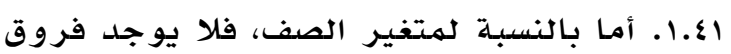
في المتوسطات بين فئة الصف الثامن وفئة الصف التاسع • الصوس

\section{نتائج اللدراسة}

أولا: النتائج المتعلقة بالسؤال الأول: مـا مستوى

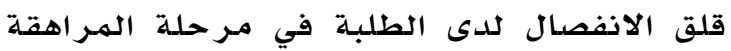
في قضاء حيفا؟ للإجابة عن هذا السؤ السال، تم

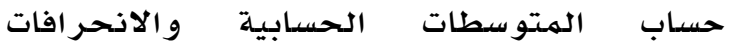
المعيارية لكل من استجابات أفراد العينة على على الهابه مقياس قلق الانفصسال ككل، و على أبعاده الثمانية كما هو مدوضح في جدول ع. ع. جدول ؛

المتوسطات الحسابية والانحرافات المعيارية لأبعاد قلق الانفصال

\begin{tabular}{|c|c|c|}
\hline \multicolumn{3}{|c|}{ مرتبة تصاعديا } \\
\hline الانحر اف المعياري & المتوسط الحسابي & 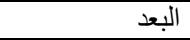 \\
\hline. .19 & $\cdot r \xi$ & ضغط الهوية \\
\hline. .10 & • & تعلق \\
\hline. .17 & • & تفرد \\
\hline .10 & rr. & توتر مؤلم \\
\hline .10 & .r. & تجنب الو اقع \\
\hline .10 & $\therefore$. & فقدان حب الذات \\
\hline$\therefore 19$ & $\therefore t$ & انهاك تقدير الذات \\
\hline .10 & דו & عدو انبة \\
\hline .10 &.$r 1$ & قلق الانفصال ككل \\
\hline
\end{tabular}

كما هو موضح في جدول ع فإن مستوى قلق

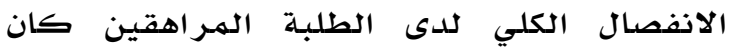

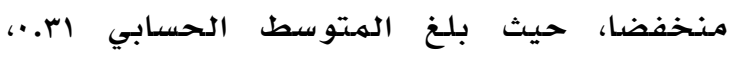
بانحر اف معياري مقداره 10..، وقد تم تصنيفه

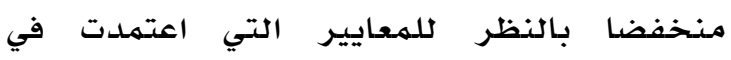
الدراسـة الحالية بما يخص مقياس قلق الانفصال.

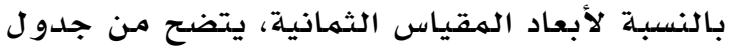

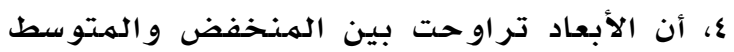

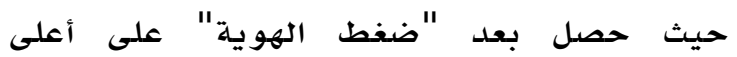

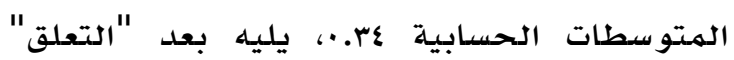

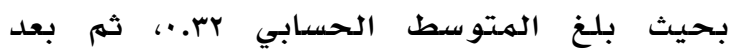

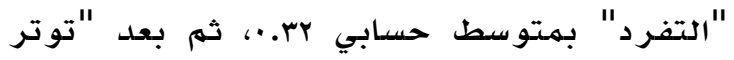

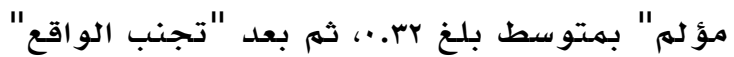

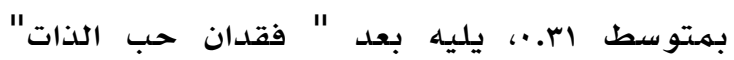

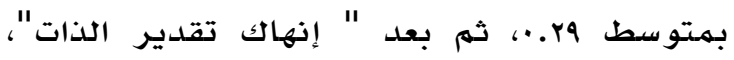

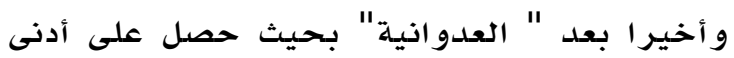

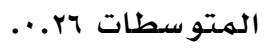

ثانيا: النتائج المتعلقة بالسؤال الثاني: ما مستوى

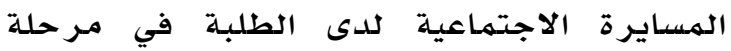
الهمر اهقة في قضاء حيفاء الهماءهاءئ للإجابة عن هذا السؤال، تم حسـاب الهـتوسط

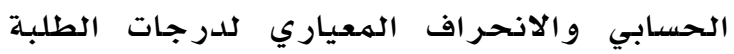


الثلاثي (3 Way ANOVA)، كما يظهر في جدول

جدول 1

تحليل التباين الثثلاثي للكثف عن دلالة الفروق بين المتوسطات

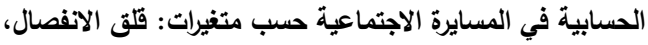

\begin{tabular}{|c|c|c|c|c|}
\hline \multicolumn{5}{|c|}{ الجنس، الصف، والتفاعل بينه } \\
\hline \multirow{2}{*}{ 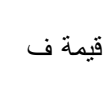 } & متوسط & درجات & مجموع & مصدر \\
\hline & المربعات & الحرية & المربعات & الثناين \\
\hline$. \cdot r \mid \varepsilon$ & $\ldots 1 \wedge$ & 1 & $\ldots 11$ & الجنس \\
\hline .01 .9 & $\ldots 9$ & 1 & $\ldots 99$ & الصف \\
\hline 1.rm4 &. $.1 \cdot v$ & $r$ & .rir & 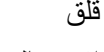 \\
\hline \multirow{3}{*}{$* \varepsilon .7 \Upsilon q$} & & & & الجنس × \\
\hline &. .499 & 1 &. .499 & الصف \\
\hline & & & & 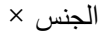 \\
\hline \multirow[t]{3}{*}{. $.1 r \varepsilon$} & $\ldots$ lr & r & ..rr & قلق \\
\hline & & & & الانفصال \\
\hline & & & & الصف × \\
\hline \multirow[t]{2}{*}{..$\times 91$} & ..ro & r & $\ldots \circ$ & قلق \\
\hline & & & & الانفصال \\
\hline \multirow[t]{3}{*}{$\cdot . r ! \varepsilon$} & $\ldots \wedge 4$ & $r .9$ & r..779 & الخطأ \\
\hline & & riq & $79 V . V Y$ & الكلا. \\
\hline & & & 9 & الحي \\
\hline
\end{tabular}

يلاحظ من خلال جدول 1 عدم وجود فروق ذات دلالة إحصائية بين متوسطات الأداء على مقياس

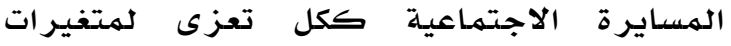
الدراسة، باستثناء وجود فرق ذا دلالة إحصائية ه..• بين متوسطات الأداء على مقياس المسايرة

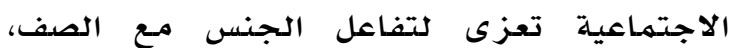
و لتوضيح أثر التفاعل مثل التفاعل بين الجنس و الصف بيانياً كما في الشكل 1. يلاحظ من الشكل ا وجود تفاعل لا رتبي، حيث كان متوسط درجات الإناث في الصف الثامن

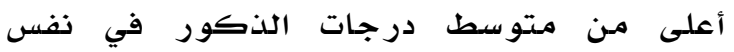
الصف، في حين كان متوسط درجات الذكور في الصف التاسع أعلى من متوسط درجات الإناث في نفس الصف.

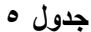
المتوسطات الحسابية والانحرافات المعيارية لمستوى المسايرة

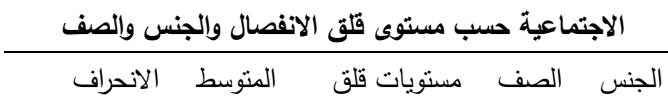

\begin{tabular}{|c|c|c|}
\hline المعياري & الحسابي & الانفصال \\
\hline . . & $1 . \leqslant 0$ & منخفض \\
\hline
\end{tabular}

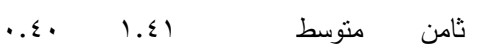

مرتفع

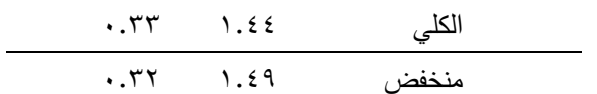

ذكور تاسع متوسط $1.07 \quad 1.89$

مرتقع

\begin{tabular}{|c|c|c|}
\hline זr. & $1.0 r$ & الكلي \\
\hline I. & $1 . \varepsilon V$ & منخفض \\
\hline .ro & $1.0 r$ & متوسط \\
\hline$\ldots T V$ & 1.7 & مرتفع \\
\hline
\end{tabular}

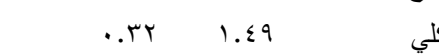

\begin{tabular}{|c|c|c|c|}
\hline. .イ & $1 . \varepsilon r$ & منخفض & \\
\hline 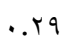 & $1 . \leqslant 9$ & متوسط & ثامن \\
\hline r & $1 . r V$ & مرتفع & \\
\hline . & $1 . \leqslant 7$ & الكلي & \\
\hline .r & $1 . r 0$ & منخفض & تاسع \\
\hline דr. & $1 . \varepsilon 1$ & متوسط & \\
\hline .rA & $1 . V r$ & مرتفع & \\
\hline
\end{tabular}

\begin{tabular}{|c|c|c|}
\hline .ro & $1 . r \Lambda$ & الكلي \\
\hline r. ro & I.rV & منخفض \\
\hline
\end{tabular}

منوسط

الكلي

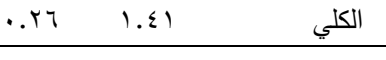

منخفض 1. 1. 1.

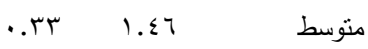

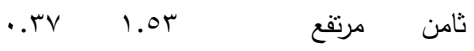

الكلي

منخفض

الكلي

تاسع مرتفع

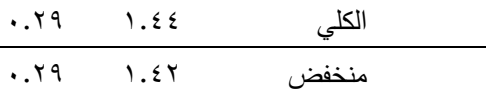

متوسط

الكلي كرتفع

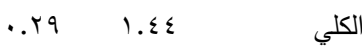

وبهدف الكثف عن مدى الدلالة الإحصائية

للفروق، فقد استخدمت الباحثتان تحليل التباين 


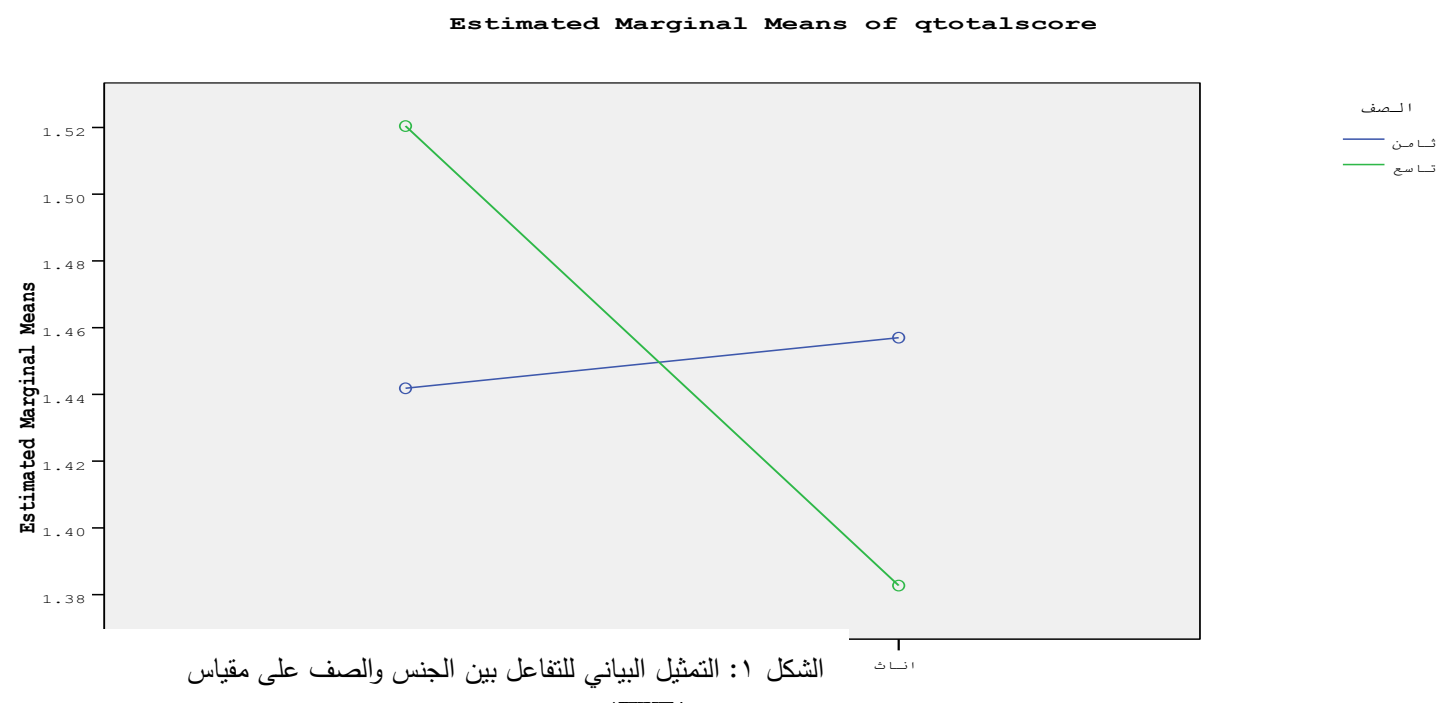

الجذرية في نمط الحياة، ووفي مستوى الاستعداد

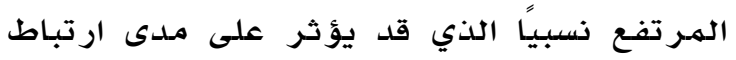
الأفر اد بمحيطهم مـما في ذلك جماعة الكمة الرفاق الأمر الذي قد يؤدي في نهاية المطاف إلى تدني مستوى قلق الانفصال.

أما بالنسبـة لأبعاد قلق الانفصال فقد حصل بُعد التعلق على أعلى الهتوسطات، و ترى الباحثتان أنه

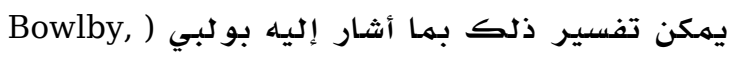

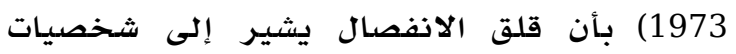

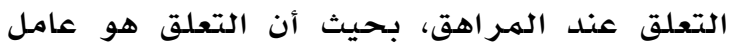

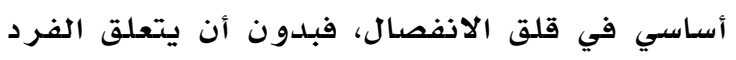
بشخصية معينة لا يمكنه أن يقلق من الانفصال

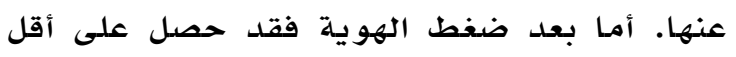
المتوسطات، وقد يعود ذلك إلى أن أهمية

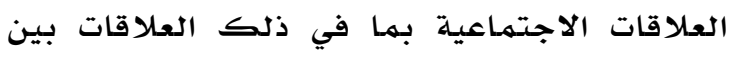
الرفاق تقلصت كثيرا في السنوات الأخيرة بوجود شبكات التواصل الاجتماعية و الالكترونية،

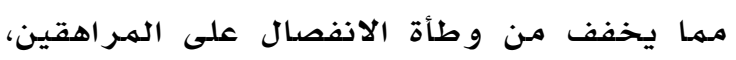
لذلك قد لا يشعر المـر اهق بنفسه معر ض للتغير على أثر الانفصدال. ثانياً: مناقشة النتائج المتعلقة بالسؤال الثاني:

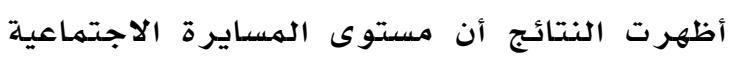
لدى الطلبة في مرحلة الهـراهقة كان آنسان منخفضاً.

\section{مناقشة النتائج}

أولاً: مناقشة النتائج المتعلقة بالسؤال الأول:

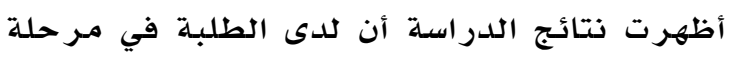

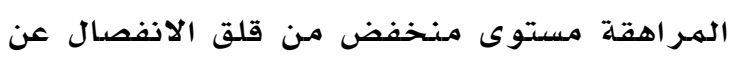

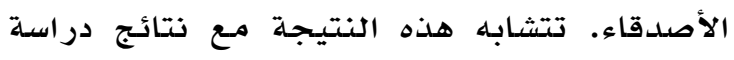

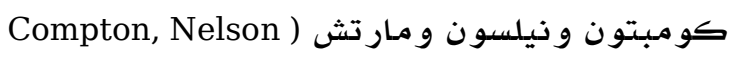

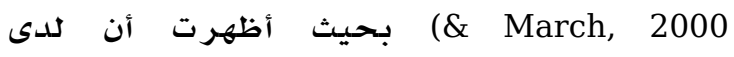

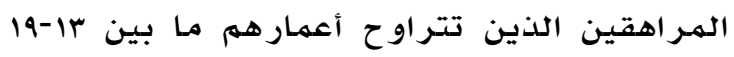

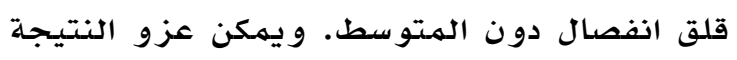

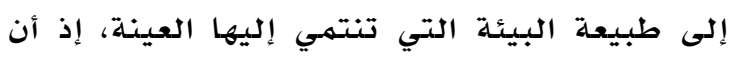

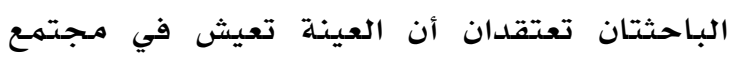

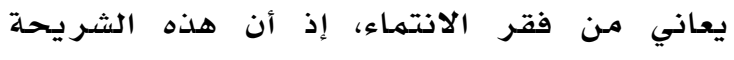

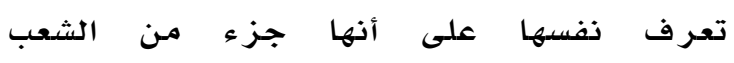
الفلسطيني، بينهما تعيش في دولة تعرف أنهاء نفسها

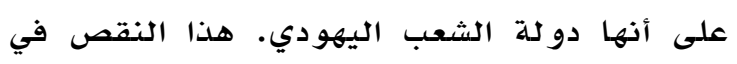

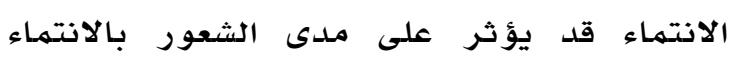
بشكل عام لأي إطار بما في ذلك جماء فماعة الرفاق

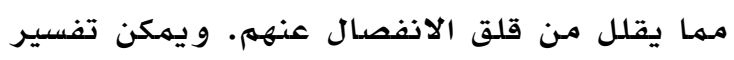
النتيجة بأن عينة الدراسة تعيث في منطقة غير

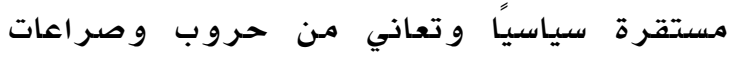

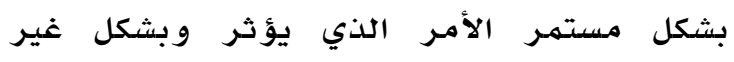

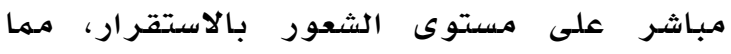
يجعل هذه الشريحة مستعدة أكثر للتغيرات 
مستوى مسايرة أي جماعة أخرى، وهذا صديح بالنسبة لمتغير القلق. و فيها يتعلق بهتغير الجنس، فقد أظهرت النتائج عدم وجود فروق ذات دلالة إحصائية ه... تعزى

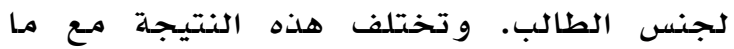

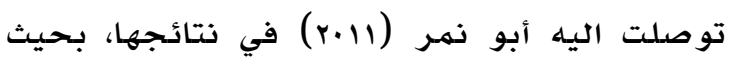
أظهرت أن المـر اهقات يسايرن أقل مـن المر اهقين،

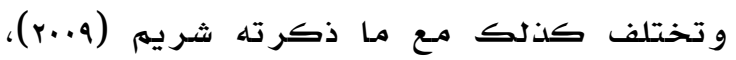
بحيث أشارت بأن مستوى المسايرة الاجتماعية

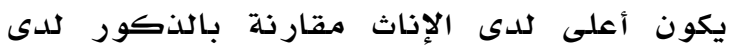

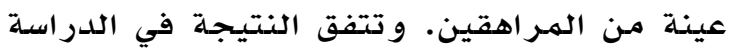
Klein, ) الحالية مـع ما أشارت إليه نتائج كلين الهين 1972) إلى أنه لا توجد فروق ذات دلادلة إحصائية في مستوى الهسايرة الاجتهماعية بين الذهور الذهرو والإناث. كما وتفسر الباحثتان ما توصلت إليه

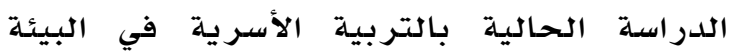
الفلسطينية المحتلة لكل من الذكور والإناث.

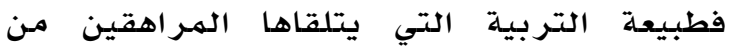

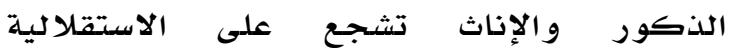
والاعتماد على الذات، و عدم الانسياق ور اء جماعة

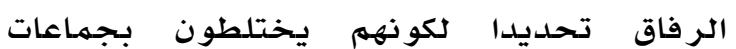
يهودية من من الرفاق يختلفون عنهم بالدين

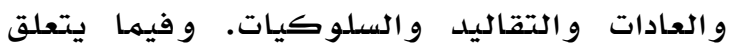

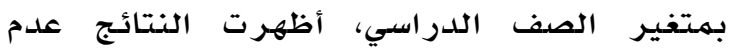

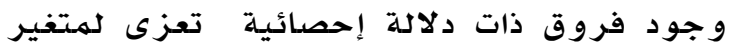

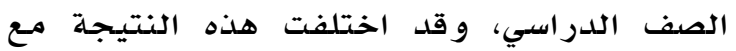
Costanzo \& Shaw, ) دراسـة كوستانزو وشوي، 1966) بحيث أثارت إلى أن مستوى المستوايرة

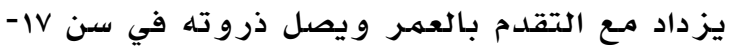
19 ثم بعد ذلك ينخفض تدريجيا. واختلفت

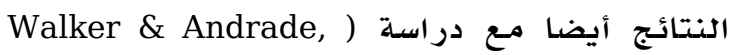
1996) التي بحثت سلوك المسايرة و علاقته بالعمر، بحيث أظهرت أن المسايرة الاجتماعية تقل مـع التقدم بالعمـر. ووترى الباحثتان أنه ربما تعود النتائج التي توصلت إليها إلى القرب بين

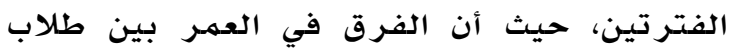

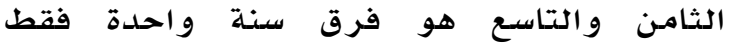
واحتمال أنها مدة غير كافيلة للحكم أن مستوى هو

$$
\text { المسايرة أعلى في صف دون الأخر. }
$$

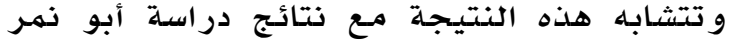

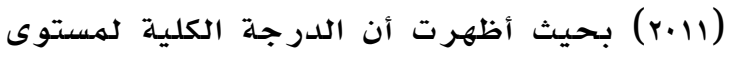

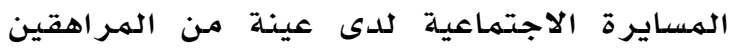
سواء مقبو لين أو مرفوضين اجتماعيا منسخفضة.

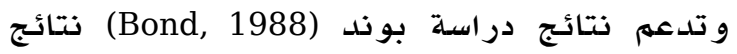
الدراسـة الحالية، بحيث أشارت إلى أن المسلهايرة

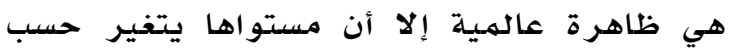
الثقافة، فتختلف بلدرجتها من بيئة إلى أخرى.

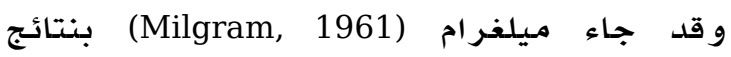
مـماثلة بحيث أظهرت نتائجه أن مدىى المسايرة الاجتماعية يختلف من دولة إلى أخرى. و تعزو

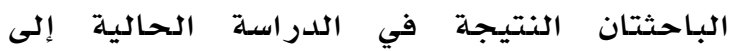
خصائص بيئة العينة، أي أن تكون البيئة

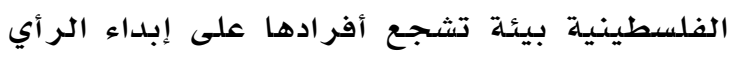
بحرية دون مجاراة أحلد، وخاصة أنها بيئة تعاني

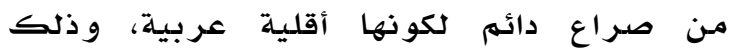
ينعكس على جميع أفرادها و لكن على الهـر اهقين بشكل خاص بحيث أنها فترة تتميز بأنهم يهتمئمون فيها بتكوين هوياتهم الشخصية و آرائهم الخاصدة.

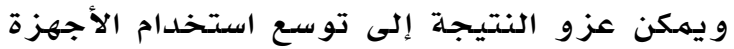

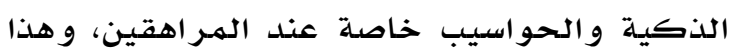
يقلل من الاهتمام بالعلاقات الاجتماعية و الالتزام بها عندهم، وبذلك تقل الحاجة إلى المسايرة للحصول على الأصدقاء أو البقاء معهم. ثالثاً: مناقشة النتائج المتعلقة بالسؤال الثالث:

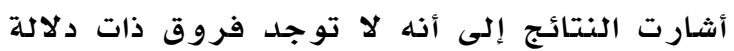

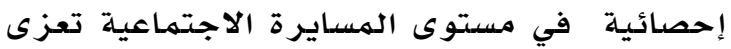

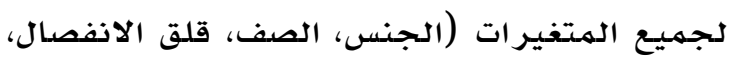

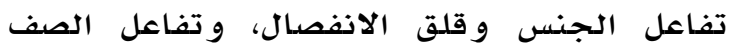

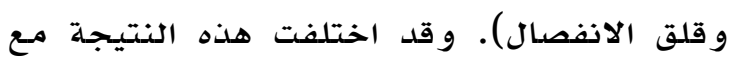

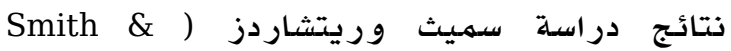
(Richards, 1967 ايجابية بين مستوى القلق و ومستوى الهسايرة الاجتماعية تحت ضغوط الجماعة، وأن للقلق أثر

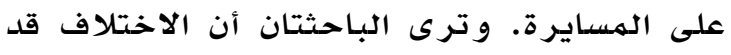

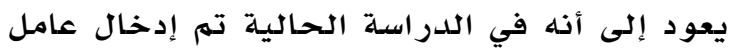

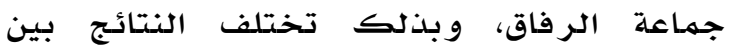

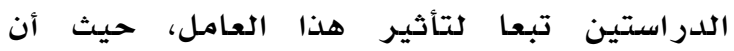
مستوى مسايرة جماعة الرفاق ربهما يختلف عن 
لجمهاعة الرفاق الهـر اهقين و الهمر اهقات.

r. دراسة تأثير مـواقع التواصل الاجتهـاعي

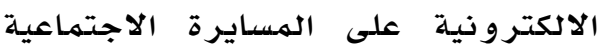
لجماعة الر فاق في حياة الهر اهقين. ع. تفعيل دور الهرشدين التربوين في المدارس لمتابعة الهر اهقين في الصفوف

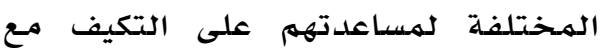

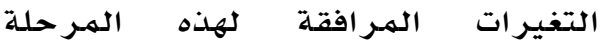

النمائية بصورة ايجيرايبة.

\section{المر اجع}

أبو زيتون، موسى (ع..r). فعالية التدريب على تأكيد الذات في خفض رون درجة الانقياد لضغوطات جمامة الرفاق وتنمية مهارات تاكيد الذات. رسالة دكتوراه غير منشورة،

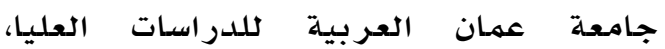
الأر دن.

أبو زيد، أحمد (11) (r). قلق الانفصال عن الأم.

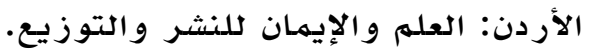
أبو نمر، أحلام (r.11). الذكاء الانفعاثي و المسايرة الاجتماعية لدى الطلبـة المقبو لين

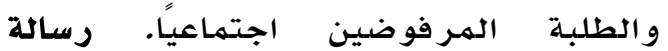
ماجستير، جامعة الير مو كك، اربلد، الأردن. بني مصطفى، منار والشريفين، أحمد (r/r). قلق الانفصال وأنماط التعلق بالأمهات البديلات لدى عينة خاصدة من الأطفال

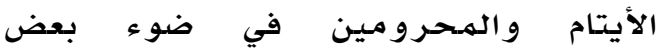
المتغير ات. مجلة جامعة قناة السويس، وبرئ .1Y7-10

تشيب، وود (r.r). معايير النمو الأطفال من

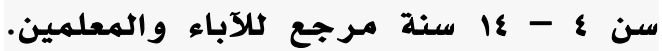
ترجمة: مدارس الظهر ان الأهلية، ج+..r. ثابت، ناصر (199r). دراسات في علم الاجتماع التربوي. الإمارات العربية المتحدة: مكتبـة النفلاح.
أما من حيث التفاعل فقد أثـارت نتائج الدراسـة إلى عدم وجود فروق ذات دلالة إحصائية في

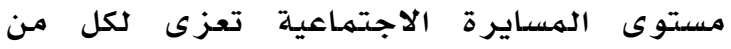
تفاعل الجنس ومستوى قلق الانفصال، و تفاعل الصف ومستوى قلق الانفصال، في حين وجدت فروق ذات دلاكة إحصائية في مستوى المسايرة الاجتهاعية تعزى للتفاعل بين الجنس والصف، حيث كان متوسط درجات الإناث في الصف الثامن أعلى مـن متوسط درجات الذكور في نفس الصف، في حين كان متوسط درجات

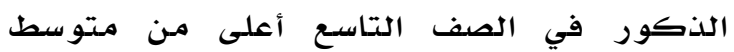
درجات الإناث في نفس الصف. و ومن الهمكن تفسير هذه النتيجة في ضوء إدهات ما أثـار إليه وودد

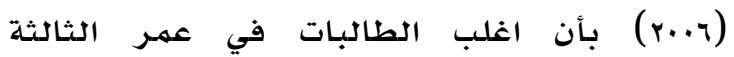

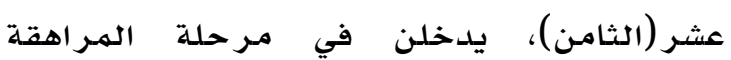
و القليل منهن يدخلن قبل هذا العمر وبذريك

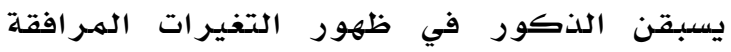

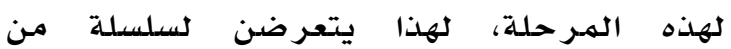
التغير ات الجسمية و النفسية والعاطفية، ويتأثرن

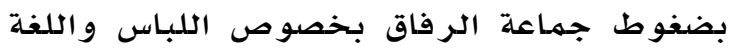

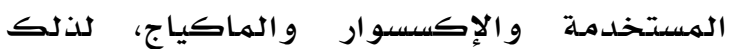
ترتفع درجة المسايرة الاجتماعية لهن في هذا

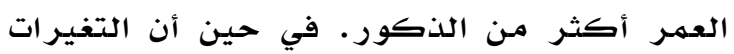

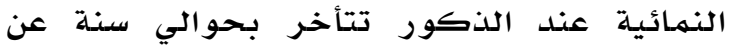
الإناث أي في عمر الر ابعة عشر (التاسـع)، فتبدأ

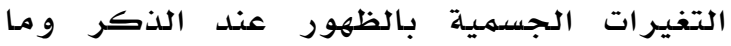
ير افقها من تغير في نبرة الصدوت و ومحاولة إظهار السيطرة و ملامح الشخصية الرجولية، و الرغبـة في الاستقلال عن الأهل وتعليماتهم و التقرب أكثر إلى الأصدقاء و مساير تهم.

التو صيـات

بعد النتائج التي تم التوصل إليها في الدراسـة الحالية، توصي الباحثتان بما يلي:

ا . إجراء المـزيد من الدراسات التي تبحثث متغير قلق الانفصال عن جماعة الرفاق لدى فئات عمرية متنوعة ورمتمايزه. r. ب بحث التأثيرات والعوامل الاجتهـاعية والثقافية و النفسية للهسايرة الاجتمـاعية 
Allen, F. H. (1955). Mother-child separation: process or event. In G. Caplan (Ed.). Emotional problems of early childhood (pp. 231-247). New York: Basic Books.

American Psychiatric Association. (2000). Diagnostic and Statistical Manual of Mental Disorders (4th ed. text revision). Washington.

Ausbel, J. (2002). Adolescent Development. NY: Prince Hall Inc.

Beesdo, K., Knappe, S., \& Pine. D. S. (2009). Anxiety and anxiety disorders in children and adolescents: Developmental issues and implications for DSM-V. Psychiatric Clinics of North America, 32(3), 483-524.

Berns, R. M. (1997). Child, Family, School, community: Socialization and Support. (4th ed.). New York: Harcourt Brace College Publishers.

Bond, M. H. (1988). Finding universal dimensions of individual variation in multi-cultural studies of values: The Rokeach and Chinese Value Surveys. Journal of Personality and Social Psychology, 55, 1009-1015.

Boree, G. (1999). Conformity and obedience. Retrieved on 7-1-2008 from: http://www.website.ship.edu/cgboer/co nformity.htm.

Bowlby, J. (1973). Attachment and Loss. New York: Basic Books.

Brown, B. B. (1990). Peer groups and peer cultures. In S. Feldman \& G. R. Elliott (Ed.). At the threshold (pp. 171-196). Cambridge: Harvard University.

Brown, B. B., Eicher, S. A., \& Petrie, S. (1986). The importance of peer group ("crowd") affiliation in Adolescence. Journal of Adolescence, 9, 73-96.

Cialdini, R.B., \& Goldstein. N.J. (2004). Social influence: compliance and conformity. Annual Review of Psycholgy, 55, 591-621.

Cobb, N. J. (2001). Adolescence: Continuity, Change and Diversity. (4th.ed). London: Mayfield Publishing Company.

Coleman, J. C. (1984). The Nature of Adolescence. London: Methuen.

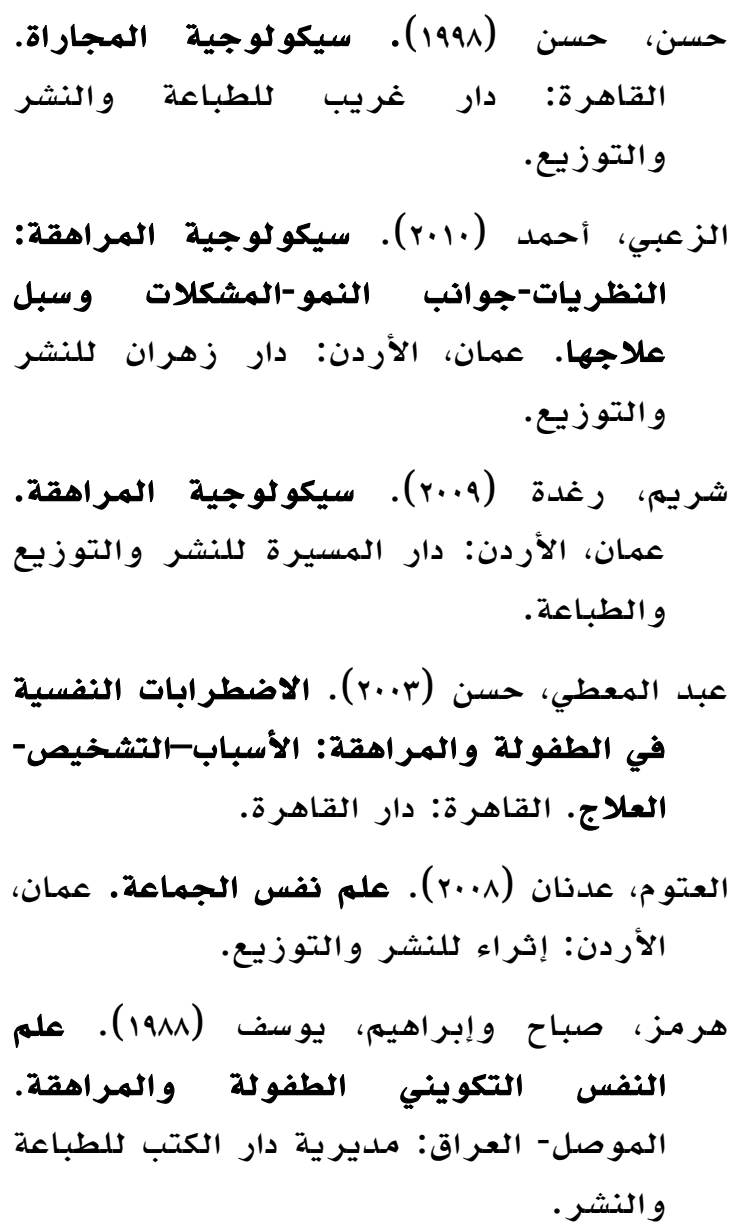


Cotterell, J. (1996). Social networks \& social influences in adolescence. New York: Routledge.

Dabkowska, M., Araszkiewicz, A., Dabkowska, A., \& Wilkosk, M. (2011). Separation anxiety in children and adolescence. In S. Selek (Ed.). Different views of anxiety disorders (pp. 313- 337). Croatia: InTech.

Deutsch, M., \& Gerard, H. B. (1955). A study of normative and informative social influence upon individual judgment. The Journal of Abnormal and Social Psychology, 51(3), 629-636.

Dubas, J. S. \& Gerris, J. R. M. (2002). Longitudinal changes in the time parents spend in activities with their adolescent children as a function of child age. Pubertal status and gender. Journal of Family Psychology, 16, 415-426.

Eisen, A. R., Raleigh, H., \& Neuhoff, C. C. (2008). The unique impact of parent training for separation anxiety disorder in children. Behavior Therapy, 39, 195-206.

Grinman, M. (2002). Belonging, conformity and social status in early adolescence. Unpublished Master Thesis. The University of British Columbia.

Hansburg, H. G. (1980). Adolescent separation anxiety: Separation disorders. New York: Robert E. Krieger.

Kearney, C. A., Sims, K. E., Pursell, C. R., \& Tillotson, C. A. (2003). Separation anxiety disorder in young children: A longitudinal and family analysis. Journal of Clinical Child and Adolescent Psychology, 32, 593-598.

Kiesler, C. A., \& Kiesler, S. B. (1969). Conformity. MA: Addison-Wesley.

Laible, D. J. Carlo, G., \& Raffaelli, M. (2000). The differential relations of parent and peer attachment to adolescent adjustment. Journal of Youth and Adolescence, 29, 45-59.

Lashbrook, J. T. (2000). Fitting in: Exploring the emotional dimension of adolescent peer pressure. Adolescence, 35 (140), 747-757. Retrieved July 18, 2003. from http:/ / www.findarticles.com/
cf_O/m2248/140_35/70777836/print.htm 1.

Last, C. G., \& Strauss, C. C. (1990). School refusal in anxiety-disorderd children and adolescents. Journal of the American Academy of Child $\mathcal{E}$ Adolescent Psychiatry, 29, 31-35.

Mazhar, K. \& Kaiser, F. (2009) Conformity of Moral Judgment in Adolescents. Rawal Medical Journal, 34 (1), 29-32.

Meenakshi, A. (1985). Parent and peer conformity in adolescents: an Indian perspective. Adolescence, 20(78), 467-478.

Merikangas, K. R., He, J., Burstein, M., Swanson, S. A., Avenevoli, S., Cui, L., et al. (2010). Lifetime Prevalence of Mental Disorders in U.S. Adolescents: Results from the National Comorbidity Survey Replication-Adolescent Supplement (NCS-A). Journal of the American Academy of Child $\mathcal{E}$ Adolescent Psychiatry, 49 (10), 980-989.

Milgram, S. (1961). Nationality and conformity. Scientific American, 205 (6), 4551.

Mofrad, S., Abdullah, R., \& Uba, I. (2010). Attachment patterns and separation anxiety. Asian Social Science, 6(11), 148-153.

Myers, D. G. (1996). Social psychology. New York: McGraw Hill.

Osborne, R. E. (1996). Self: An eclectic approach. Boston: Allyn and Bacon.

Peer group, (n.d.). The American Heritage ${ }^{\circledR}$ New Dictionary of Cultural Literacy. Third Edition. Retrieved November 12, 2012, from Dictionary.com website: http:/ / dictionary.reference.com/browse/ peer group.

Provence, S. (1987). Psychoanalytic views of separation in infancy and early childhood. In J. Bloom-Feshbach \& S. BloomFeshbach (Eds.). The psychology of separation and loss (pp. 87-108). San Francisco \& London: Jossey-Bass Publishers.

Santrock, J. W. (2003). Adolescence (9th ed.). New York: McGraw-Hill. 
Seligman, L. D., \& Wuyek, L. A. (2007). Correlates of separation anxiety symptoms among first-semester college students: an exploratory study. The Journal of Psychology, 141(2), 135-145.

Smith, K. \& Richards. H. (1967). Effects of rational appeal of anxiety on conformity behavior. Journal of Personality and Social Psychology, 5(1), 122-126.

Sontag, L. M., Graber. J. A., \& Clemans, K. H. (2011). The role of peer stress and pubertal timing on symptoms of psychopathology during early adolescence. Journal of Youth and Adolescence, 40 (10), 1371-1382.

Strauss, C. C., Lahey, B. B., Frick, P., Frame, C. L., \& Hynd, G. W. (1988). Peer social status of children with anxiety disorders. Journal of Consulting and Clinical Psychology, 56(1), 137-141.

Taylor, S. E., Peplau, L., \& Sears, D. O. (2000). Social Psychology (10 th $^{\text {Ed.). }}$. Englewood Cliffs, NJ: Prentice Hall.

Teunnissen, H. A., Spijkerman.R., Prinstein, M. J., Cohen, G. L., Engels, R. C. M. E., \& Scholte, R. H. (2012). Adolescents' conformity to their peers' pro-alcohol and anti-alcohol norms: the power of popularity. Alcoholism: Clinical and Experimental Research, 36, 1257-1269.

Wiesse, J., \& Wienstock-Kroczek. E. (1989). Anxiety in adolescents and its significance for psychoanalysis. Adolescents, 24, 403410. 